2011s-05

\title{
Optimum Commodity Taxation with a Non-Renewable Resource
}

\author{
Julien Daubanes, Pierre Lasserre
}

\begin{tabular}{c}
\hline Série Scientifique \\
Scientific Series
\end{tabular}

\section{Montréal}

Janvier 2011

(C) 2011 Julien Daubanes, Pierre Lasserre. Tous droits réservés. All rights reserved. Reproduction partielle permise avec citation du document source, incluant la notice $($.

Short sections may be quoted without explicit permission, if full credit, including () notice, is given to the source.
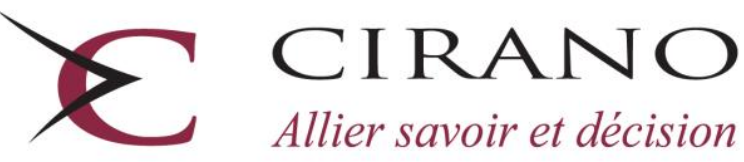

Allier savoir et décision

Centre interuniversitaire de recherche en analyse des organisations 


\section{CIRANO}

Le CIRANO est un organisme sans but lucratif constitué en vertu de la Loi des compagnies du Québec. Le financement de son infrastructure et de ses activités de recherche provient des cotisations de ses organisations-membres, d'une subvention d'infrastructure du Ministère du Développement économique et régional et de la Recherche, de même que des subventions et mandats obtenus par ses équipes de recherche.

CIRANO is a private non-profit organization incorporated under the Québec Companies Act. Its infrastructure and research activities are funded through fees paid by member organizations, an infrastructure grant from the Ministère du Développement économique et régional et de la Recherche, and grants and research mandates obtained by its research teams.

\section{Les partenaires du CIRANO}

Partenaire majeur

Ministère du Développement économique, de l'Innovation et de l'Exportation

\section{Partenaires corporatifs}

Banque de développement du Canada

Banque du Canada

Banque Laurentienne du Canada

Banque Nationale du Canada

Banque Royale du Canada

Banque Scotia

Bell Canada

BMO Groupe financier

Caisse de dépôt et placement du Québec

Fédération des caisses Desjardins du Québec

Financière Sun Life, Québec

Gaz Métro

Hydro-Québec

Industrie Canada

Investissements PSP

Ministère des Finances du Québec

Power Corporation du Canada

Raymond Chabot Grant Thornton

Rio Tinto

State Street Global Advisors

Transat A.T.

Ville de Montréal

\section{Partenaires universitaires}

École Polytechnique de Montréal

HEC Montréal

McGill University

Université Concordia

Université de Montréal

Université de Sherbrooke

Université du Québec

Université du Québec à Montréal

Université Laval

Le CIRANO collabore avec de nombreux centres et chaires de recherche universitaires dont on peut consulter la liste sur son site web.

Les cahiers de la série scientifique (CS) visent à rendre accessibles des résultats de recherche effectuée au CIRANO afin de susciter échanges et commentaires. Ces cahiers sont écrits dans le style des publications scientifiques. Les idées et les opinions émises sont sous l'unique responsabilité des auteurs et ne représentent pas nécessairement les positions du CIRANO ou de ses partenaires.

This paper presents research carried out at CIRANO and aims at encouraging discussion and comment. The observations and viewpoints expressed are the sole responsibility of the authors. They do not necessarily represent positions of CIRANO or its partners. 


\title{
Optimum Commodity Taxation with a Non-Renewable Resource*
}

\author{
Julien Daubanes ${ }^{\dagger}$, Pierre Lasserre ${ }^{+\frac{\hbar}{*}}$
}

\begin{abstract}
Résumé
La taxation optimale des biens cherche à lever des revenus fiscaux donnés en minimisant les distorsions. Nous réexaminons la règle de l'élasticité inverse de Ramsey en présence de ressources non-renouvelables à la Hotelling. Sous les hypothèses standard des littératures de l'extraction des ressources non-renouvelables et de la taxation optimale, une ressource non-renouvelable doit être taxée en priorité, quelles que soient l'élasticité de sa demande et l'élasticité de la demande pour les autres biens. Elle doit l'être à un taux plus élevé qu'un autre bien dont la demande est aussi élastique et, contrairement au taux s'appliquant aux biens conventionnels, ce taux doit varier dans le temps. La taxe dépend des besoins en revenus fiscaux; plus ils sont élevés, plus le prix correspondant s'approche du prix de monopole.

Les réserves minérales constituent une forme de capital que taxent les royalties; Chamley a montré qu'il est néfaste de taxer le capital à très long terme. Au contraire, même lorsque les réserves à extraire dépendent du traitement fiscal de l'extraction, en l'absence de toute subvention à l'exploration, le taux optimal de la taxe obéit à la même règle d'élasticité inverse que les biens conventionnels dont l'offre est parfaitement élastique. En fait, il y a une infinité de combinaisons optimales de taxes à l'extraction et de subventions à la constitution de réserves. Si le gouvernement n'est pas en mesure de s'engager à s'abstenir de taxer les producteurs, ces derniers sont entièrement expropriés et ce sont des subventions qui doivent financer la constitution de réserves. En général, la taxe optimale de Ramsey cause une distorsion tant sur le profil d'extraction (comme lorsque les réserves sont données) que sur le volume des réserves lorsque celles-ci sont endogènes. Lorsque cette dernière distorsion est le seul effet de la taxe, elle obéit à une règle proche de celle qui s'applique aux biens conventionnels dont l'offre est élastique.
\end{abstract}

Mots clés : Taxation optimale des biens, règle de l'élasticité inverse, ressources non-renouvelables, ressource hotellienne, élasticité de l'offre, élasticité de la demande, taxation du capital.

\footnotetext{
* We thank participants at various seminars and conferences: University Panthéon-Assas (Paris II) 2009; ETH Zurich 2010; Montreal Natural Resources and Environmental Economics Workshop 2010; Toulouse Business School 2010; University Panthéon-Sorbonne (Paris I) 2010; SURED Ascona 2010; Bonn Max Planck Institute 2010; Journées Louis-André Gérard-Varet 2010; WCERE Montréal 2010; Helsinki School of Economics 2010. Particular thanks go to Gérard Gaudet, John Hartwick, Martin Hellwig, Matti Liski and Ngo Van Long. Financial support from the Social Science and Humanities Research Council of Canada, the Fonds Québécois de recherche pour les sciences et la culture, the CER-ETH at ETH Zurich, the CIREQ, and the Agence Nationale de la Recherche (ANR-09-BLAN-0350-01) is gratefully acknowledged.

${ }^{\dagger}$ CER-ETH, Center of Economic Research at ETHZ, Swiss Federal Institute of Technology Zurich, e-mail address: jdaubanes@ethz.ch.

† Corresponding author. Département des sciences économiques, Université du Québec à Montréal, CIRANO and CIREQ, e-mail address: lasserre.pierre@ uqam.ca, address: Université du Québec à Montréal, Département des sciences économiques, C.P. 8888, Succursale Centre-Ville, Montréal, Québec, Canada H3C 3P8.
} 


\begin{abstract}
Optimum commodity taxation theory asks how to raise a given amount of tax revenue while minimizing distortions. We reexamine Ramsey's inverse elasticity rule in presence of Hotelling-type nonrenewable natural resources. Under standard assumptions borrowed from the non-renewableresource-extraction and from the optimum-commodity-taxation literatures, we show that a nonrenewable resource should be taxed in priority whatever its demand elasticity and whatever the demand elasticity of regular commodities. It should also be taxed at a higher rate than other commodities having the same demand elasticity and, while the tax on regular commodities should be constant, the resource tax should vary over time. The appropriate taxation rule depends on the government's revenue needs; the higher these needs, the closer the consumer price to the monopoly price.

Reserves are a form of capital and royalties tax its income; our results contradict Chamley's conclusion that capital should not be taxed at all in the very long run. When reserves to be extracted are responsive to the taxation of extraction, in the absence of any subsidy to reserve discoveries, the optimal tax rate on extraction obeys an inverse elasticity rule almost identical to that of a commodity whose supply is perfectly elastic. As a matter of fact, there is a continuum of optimal combinations of extraction taxes and subsidies. When the government cannot commit, extraction rents are completely expropriated and subsidies are maximum. In general the optimum Ramsey tax not only causes a distortion of the extraction path, as happens when reserves are given, but also distorts the level of reserves developed for extraction. When that distortion is the sole effect of the tax, it is determined by a rule reminiscent of the inverse elasticity rule applying to elastically-supplied commodities.
\end{abstract}

Keywords: Optimum commodity taxation, inverse elasticity rule, non-renewable resources, hotelling resource, supply elasticity, demand elasticity, capital income taxation.

Codes JEL : Q31, Q38, H21 


\section{Introduction}

The theory of optimal commodity taxation addresses the following question: how should a government concerned with total welfare distribute the burden of commodity taxation across sectors in such a way as to collect a set amount of tax income while minimizing the deadweight loss? The literature originated with Ramsey (1927) and Pigou (1928) and was consolidated by Baumol and Bradford (1970), Atkinson and Stiglitz (1980), and others.

Its most famous result is the "inverse elasticity rule" which says that, under notso-restrictive conditions, commodity taxes are optimal when set proportional to the reciprocal of the price elasticity of demand characterizing each market in the economy. Although the inverse elasticity rule does not always survive extensions to general setups, it is considered to give a good and general intuition to the choice of optimal commodity taxes: commodity taxes cause distortions; the distortion introduced by the tax on any specific commodity is lower, the lower the elasticity of demand on that market; hence, if the objective is to spread evenly the social cost of the distortions associated with commodity taxation, the tax should be heavier in lower elasticity markets and vice versa.

In this paper we reexamine "optimal commodity taxation" and the "inverse elasticity rule" in presence of non-renewable natural resources. Is there any reason to give any particular attention to non-renewable resources in that context? ${ }^{1}$ Atkinson and Stiglitz (1976) showed that under a condition of separability of leisure and consumption choices, optimal non-linear income taxation makes commodity taxation useless. On this see also Mirrlees (1976), Christiansen (1984), Konishi (1995) and Kaplow (2006). However, the role of differential commodity taxation received a renewed attention recently. Cremer et al. (2001) showed that separability is not sufficient when individuals differ in their endowment. Saez (2002), extending the analysis to heterogeneous tastes within

\footnotetext{
${ }^{1}$ It is often noted that energy demand, oil demand in particular, is relatively price inelastic (Berndt and Wood, 1975; Pindyck, 1979). Recent contributions synthesized by Krichene (2002) deliver the same message. According to the optimum commodity taxation theory, this would call for relatively high oil taxes.
} 
income levels, made clear that Atkinson-Stiglitz's result relies on the strong homogeneity of individuals. Blomquist and Christiansen (2008) showed how commodity taxes alleviate extreme self-selection constraints. Assuming non-separable but homogeneous preferences and imperfect competition in the labor market, Aronsson and Sjögren (2003) emphasized that optimum commodity taxes should depend on their specific effects on unemployment. Other considerations justifying differential commodity taxation in the absence of externalities include the production technology (Naito, 1999; Saez, 2004), tax evasion (Boadway et al., 1994), uncertainty (Cremer and Gahvari, 1995), or imperfect coordination between fiscal authorities (Belan et al., 2008, footnote 1, page 1739).

The non-renewability of a natural resource further adds an intertemporal dimension to the optimal commodity taxation problem. In such a dynamic context, Stiglitz (1976) and Lewis et al. (1979) have shown the crucial role played by demand elasticity in a resource monopoly, culminating in the special isoelastic case where monopoly power becomes entirely eroded by the necessity for the monopoly to compete with itself intertemporally. Does the intertemporal nature of non-renewable resource taxation confer a special role to demand elasticity as in the monopoly case?

As a matter of fact, there already exists an "elasticity rule" of optimal non-renewable resource taxation. This rule is due to Bergstrom (1982) who showed that a country should set its national excise $\operatorname{tax}^{2}$ rate according to a "rule relating the equilibrium excise tax rates to demand elasticities and market shares". Although Bergstrom seeks to characterize optimal excise tax rates on non-renewable resources, the problem he addresses is very different from the conventional Ramsey-Pigou optimal taxation problem. It is a problem of tax competition between countries producing and consuming a resource and a numeraire. Both goods are traded internationally and each country seeks to maximize its own welfare by choosing its excise tax selfishly. The optimal taxes reflect a non-cooperative Nash equilibrium where no unilateral change in a country's tax will benefit the citizens of that country given the taxes chosen by other countries.

\footnotetext{
${ }^{2} \mathrm{An}$ excise tax is a percentage levied on the revenues from the sale of a resource; in this paper there is no distinction between an excise tax and a commodity tax.
} 
How should the Ramsey-Pigou inverse elasticity rule of optimal taxation be modified in presence of non-renewable resources? Facing a revenue constraint introduces a monopolistic revenue maximization component into the objective of Ramsey's government, which gives it some similarity with Bergstrom decision maker's selfish objective and with Stiglitz's monopoly. In fact we find that, when government revenue needs are extreme, Ramsey's rule becomes equivalent to static monopoly pricing and takes the same form for the non-renewable resource and conventional goods. This isomorphism between optimum commodity taxation and monopoly pricing is well known and does not come as a surprise.

Under the standard assumptions made in the non-renewable resource extraction and the optimum commodity taxation literatures, it turns out that a non-renewable resource should be taxed in priority whatever its demand elasticity and whatever the elasticity of the demand for other, produced, commodities. Only when the tax revenue needs of the government exceed some threshold, do elasticities become relevant.

The irrelevance of demand elasticity when government revenue needs are relatively low appears surprising at first sight as no such distinction between high and low revenue needs is to be found in usual formulations of the Ramsey-Boiteux optimum tax. However it is useful to take a wider view here and remember the remark of Dasgupta and Stiglitz (1972) to the effect that the problem of optimum commodity taxation is most interesting in cases "where government losses cannot be covered by the exclusive selection of optimum profit taxes." (page 92). The reason is that distortionary commodity taxes are not needed in such cases. The presence of a Hotelling sector in the economy introduces resource scarcity rents. While such rents are not conventional profits, our result implies that taxing away rents is not unlike taxing away profits from the point of view of optimum commodity taxation. It shows that distortionary commodity taxes should not be introduced in non-resource sectors until the possibility to tax resource rents by non-distortionary commodity taxes has been fully exploited. The distinction between low and high government-revenue needs then has a clear interpretation: revenue needs are low when they can be satisfied by commodity taxation without imposing any 
distortion on the economy; revenue needs are high otherwise.

We adhere to the conventional Ramsey-Pigou framework. ${ }^{3}$ That is, direct taxation (of profits, of incomes) is not an option; lump-sum transfers are impossible; indirect, linear taxes or subsidies can be applied on any commodity or service; taxes (or subsidies) may take the form of ad valorem taxes or of unit taxes, proportional to quantities. The government is not concerned with individual differences ${ }^{4}$; in fact we assume a representative consumer. The optimal supply of public goods is not addressed either; we assume that the government faces exogenous financial needs in order to fulfill its role as a supplier of public goods so that the government's problem is to raise that amount of revenues in the least costly way, given the available tax instruments.

While this framework explicitly rules out the taxation of capital income, whether in the form considered by Chamley (1986), or in a form mimicking profit taxation as with Lucas' (1990) capital levies, some results will be related to the taxation of capital income because applying a commodity tax to resource extraction over time is not unlike taxing the income of the resource capital. However we show that Chamley's result that the optimal tax rate on capital should be zero in the long run does not apply to such capital as a stock of non-renewable resource, despite the fact that the generation of reserves by exploration is analogous to the generation of capital by investment.

It is conventional to establish the inverse elasticity rule of optimal commodity taxation under the simplifying assumption that supply elasticity is infinite, so that distortions are determined on the demand side. Although not equivalent to it, this assumption may be seen as the counterpart of the assumption that profits are not taxed: indeed under constant returns profits are zero. On the other hand, the supply of a non-renewable resource is not infinitely elastic even if marginal extraction cost is constant. This is

\footnotetext{
${ }^{3}$ For reasons that go beyond the purpose of this paper, linear levies based on quantities are by far the most common form of resource taxes (see, e.g. Boadway and Flatters, 1993); so adherence to the Ramsey-Pigou framework enhances rather than it reduces the empirical relevance of the analysis.

${ }^{4}$ Belan et al. (2008) study optimal commodity taxation with a limited the number of different tax rates and a continuum of heterogeneous individuals weighted differently by the government. As a result, each commodity is assigned a social weight by the government. The authors find the optimal taxes to obey Ramsey's inverse elasticity rule.
} 
because the short-run supply of a non-renewable resource is not a myopic decision; it consists in allocating the production from a finite stock of reserves over time. A resource supplier that increases production at any date reduces the stock of reserves remaining for production in subsequent periods. Taking this consideration into account implies that the instantaneous supply elasticity is finite. An extreme example of this link between the fixity of long-run reserves and short-run supply occurs when a constant-rate commodity tax is imposed on a costlessly extracted resource, as assumed by Bergstrom. In such a special case, short-run supply is not affected by the tax.

In this paper, we do not impose any restriction on the evolution of taxes over time. In order to facilitate comparisons with the conventional analysis involving non-resource sectors, we proceed in several steps. In the first step, presented in Section 2, we follow the traditional optimal taxation literature in assuming constant marginal costs of production. This implies that supply is infinitely elastic in non-resource sectors as should be the case in a long-run analysis when no factors are fixed. In the non-renewable resource sector, the same assumption on the technology, constant marginal extraction cost, implies that there is no limit to short-run supply; however Hotelling's long-run exhaustibility of the resource retains its central role. It is in that setup that we obtain the result mentioned above that the resource should be taxed in priority over producible commodities.

In a third section, we extend the analysis to increasing marginal costs of production/extraction, so that short-run supply elasticities are no longer assumed infinite. In this case, the non-renewable resource should also be taxed in priority.

In Section 4, we do away with the Hotelling assumption that the total level of reserves is given. Instead we assume that the production of reserves is determined by the combination of subsidies or tax rebates that the owner receives toward the production of reserves, and net-of-tax rents that the owner will derive during the extraction phase. This means that resource supply is allowed to be elastic not only in the short run as in the first part of the paper, but also in the long run. A first implication is that resources should not in that case be singled out as primary targets for optimal commodity 
taxation. As in the original paper of Ramsey, and as Gaffney (2009) has emphatically pointed out, supply elasticity combines with demand elasticity to determine how the burden of the deadweight loss associated with the tax should be spread across sectors.

If the government wants net extraction profits to give producers incentives to develop reserves, it must be able to commit not to tax away the totality of extraction rents. Alternatively, if the government taxes away all extraction rents, it must compensate firms by subsidies or tax breaks prior to extraction. In fact, we show that there exists a continuum of mixed systems, combining subsidies toward reserve supply with taxes on extraction, that achieves government's objectives in terms of reserve development and tax revenues in the multi-sector Ramsey economy. Such combinations depict most commonly observed extractive resource tax systems including the polar case where the government is unable to commit not to expropriate firms by taxing away extraction rates. This inability to commit may justify the nationalization of an extraction sector: the government then appropriates itself the totality of resource rents, after financing the totality of reserve development costs.

In the absence of subsidies toward reserve discoveries and development, we find that the optimal taxation of the resource obeys the same inverse elasticity rule as conventional commodities. However, in the dynamic context of non-renewable resource extraction this rule does not have the familiar interpretation that setting the tax proportional to the inverse of the elasticity spreads the distortion evenly across sectors; as a matter of fact the extraction profile may even be undistorted under the optimal rule. In general, nonetheless, the optimal tax rate on resource extraction is always strictly higher than the tax rate on any commodity having the same demand elasticity and whose supply is perfectly elastic.

Extraction taxes not only distort the extraction path, but also the induced level of reserves. By focusing on a particular case where the later effect can be isolated out, we find a rule that characterizes the distortion of reserves. This rule is reminiscent of the inverse elasticity rule applying to elastically-supplied conventional goods and services, provided the supply and demand elasticity concepts are defined in a way that is relevant 
to Hotelling resources.

Proofs that are economically enlightening are provided in the main text; proofs involving algebraic manipulations are relegated to the Appendix.

\section{A model of optimal commodity taxation with a non-renewable resource: the case of constant marginal costs}

There are $n$ produced commodities indexed by $i=1, \ldots, n$, and one non-renewable resource indexed by $s$ and extracted from a finite reserve stock $S_{0}$. The assumption of a single non-renewable resource simplifies the exposition without affecting the generality of the results. At each date $t \geq 0$, quantity flows are denoted by $x_{t} \equiv\left(x_{1 t}, \ldots, x_{n t}, x_{s t}\right)$. Storage is not possible, so that goods must be consumed as they are produced. Producer prices are $p_{t} \equiv\left(p_{1 t}, \ldots, p_{n t}, p_{s t}\right)$ and goods are taxed at unit levels $\theta_{t} \equiv\left(\theta_{1 t}, \ldots, \theta_{n t}, \theta_{s t}\right)$ so that the representative consumer faces prices $q_{t}=p_{t}+\theta_{t}$. Taxes must be such that they leave non-negative profits to producers. In the case of the non-renewable resource, this requires that the rent accruing to producers over the entire life of the mine be non negative. Taxes that meet these conditions will be called feasible.

Since the resource is non renewable it must be true that

$$
\int_{0}^{+\infty} x_{s t} d t \leq S_{0}
$$

where $S_{0}$ is the initial size of the depletable stock.

For given feasible taxes $\Theta \equiv\left\{\theta_{t}\right\}_{t \geq 0}$, competitive markets lead to the equilibrium allocation $\left\{\widetilde{x}_{t}\right\}_{t \geq 0}$ where $\widetilde{x}_{t}=\left(\widetilde{x}_{1 t}, \ldots, \widetilde{x}_{n t}, \widetilde{x}_{s t}\right) .{ }^{5}$ Under the set of taxes $\Theta$, this intertemporal allocation is second-best efficient.

Defining social welfare as the cumulative discounted sum of instantaneous utilities $W\left(x_{t}\right)$, the optimum commodity taxation problem consists in choosing a feasible set of taxes $\Theta$ in such a way as to maximize welfare while raising a given level of discounted revenue $R_{0} \geq 0$ :

$$
\max _{\Theta} \int_{0}^{+\infty} W\left(\widetilde{x}_{t}\right) e^{-r t} d t
$$

\footnotetext{
${ }^{5}$ In the rest of the paper, a " " on top of a variable or function means that the variable or function is evaluated at the competitive market equilibrium.
} 


$$
\text { subject to } \int_{0}^{+\infty} \theta_{t} \widetilde{x}_{t} e^{-r t} d t \geq R_{0} .
$$

It is assumed that the set of feasible taxes capable of collecting $R_{0}$ is not empty.

The tax revenue constraint (3) does not bind the government at any particular date because financial markets allow expenditures to be disconnected from revenues. The government accumulates an asset $a_{t}$ over time by saving tax revenues:

$$
\dot{a}_{t}=r a_{t}+\theta_{t} \widetilde{x}_{t}
$$

where the initial amount of asset is normalized to zero and

$$
\lim _{t \rightarrow+\infty} a_{t} e^{-r t}=R_{0}
$$

Thus the problem of maximizing (2) subject to (3) can be replaced with the maximization of (2) subject to (4) and (5), by choice of a feasible set of taxes.

As in Ramsey (1927, page 55), Baumol and Bradford (1970), or Atkinson and Stiglitz (1980), we assume that the demand $D_{i}\left(q_{i t}\right)$ for each commodity $i$ or $s$ depends only on its own price, with $D_{i}^{\prime}()<$.0 . Moreover, following Baumol and Bradford (1970), Atkinson and Stiglitz (1980) and many other treatments of optimal commodity taxation, we assume in this section that the supply of each commodity is perfectly elastic, i.e. that marginal costs of production are constant. Let $c_{i} \geq 0$ be the marginal cost of producing $\operatorname{good} i=1, \ldots, n$.

In the case of the non-renewable resource, the supply is determined by Hotelling's rule under conditions of competitive extraction. Consistently with our assumption of constant marginal costs of production, we assume in this section that the unit cost of extracting the resource is constant ${ }^{6}$, equal to $c_{s} \geq 0$.

However, this does not imply that the producer price of the non-renewable resource reduces to this marginal cost; Hotelling's analysis shows supply to be determined in competitive equilibrium by the so-called "augmented marginal cost" condition:

$$
\widetilde{p}_{s t}=c_{s}+\widetilde{\eta}_{t}
$$

\footnotetext{
${ }^{6}$ In the next section, we extend the results to non-perfectly-elastic supplies (increasing marginal costs of production and increasing marginal costs of extraction).
} 
where $\widetilde{\eta}_{t}$ is the current-value unit Hotelling's rent accruing to producers; it depends on the tax and the level of initial reserves, and must grow at the rate of discount over time. In competitive Hotelling equilibrium,

$$
\widetilde{\eta}_{t}=\widetilde{\eta}_{0} e^{r t}
$$

At any date, the net consumer surplus, producer surplus, and resource rents in competitive equilibrium are respectively

$$
\begin{gathered}
C S\left(\widetilde{x}_{t}\right)=\sum_{i=1, \ldots, n, s} \int_{0}^{\widetilde{x}_{i t}} D_{i}^{-1}(u) d u-\sum_{i=1, \ldots, n, s}\left(\widetilde{p}_{i t}+\theta_{i t}\right) \widetilde{x}_{i t}, \\
P S\left(\widetilde{x}_{t}\right)=\sum_{i=1, \ldots, n, s} \widetilde{p}_{i t} \widetilde{x}_{i t}-\sum_{i=1, \ldots, n, s} c_{i} \widetilde{x}_{i t}-\widetilde{\eta}_{t} \widetilde{x}_{s t}
\end{gathered}
$$

and

$$
\phi\left(\widetilde{x}_{s t}\right)=\widetilde{\eta}_{t} \widetilde{x}_{s t}
$$

Define $W\left(\widetilde{x}_{t}\right)$ in problem (2) as the sum of net consumer surplus, net producer surplus, and resource rents accruing to resource owners ${ }^{7}$. The present-value Hamiltonian associated with the problem of maximizing cumulative discounted social welfare (2) under constraints (4) and (5) resulting from the budget requirement of the government is

$$
\mathcal{H}\left(\widetilde{x}_{t}, a_{t}, \theta_{t}, \lambda_{t}\right)=\left(C S\left(\widetilde{x}_{t}\right)+P S\left(\widetilde{x}_{t}\right)+\phi\left(\widetilde{x}_{s t}\right)\right) e^{-r t}+\lambda_{t}\left(r a_{t}+\theta_{t} \widetilde{x}_{t}\right),
$$

where $\lambda_{t}$ is the co-state variable associated with $a_{t}$ while $\theta_{t}$ is the vector of control variables. $\lambda_{t}$ can be interpreted as the current unit cost of levying one dollar of presentvalue revenues through taxes. From the maximum principle, $\dot{\lambda}_{t}=-\frac{\partial \mathcal{H}}{\partial a_{t}}$, so that $\lambda_{t}=$ $\lambda e^{-r t}$, where $\lambda$ is the present-value unit cost of levying tax revenues. Indeed tax revenues must be discounted according to the date at which they are collected. $\lambda$ is equal to

\footnotetext{
${ }^{7}$ Although changes in current taxes may affect current tax revenues, the budget constraint of the government applies only over the entire optimization period. The revenue requirements being treated as given over that period, they enter the general problem as a constant and thus no amount of redistributed taxes needs to enter the objective.

${ }^{8}$ This formulation has the advantage of making the value of the resource as a scarce input explicit; it would also apply if producers were not owners of the resource but were buying the resource from its owners at its scarcity price $\widetilde{\eta}_{t}$.
} 
unity when there is no deadweight loss associated with taxation; it is higher than unity otherwise $^{9}$.

\subsection{Optimal taxation of conventional goods}

Assuming that there exist feasible taxes that yield an interior solution to the problem, the first-order condition for the choice of the $\operatorname{tax} \theta_{i t}$ on good $i=1, \ldots, n$ is

$$
\left[D_{i}^{-1}\left(\widetilde{x}_{i t}\right)-\theta_{i t}-c_{i}\right] \frac{d \widetilde{x}_{i t}}{d \theta_{i t}}-\widetilde{x}_{i t}+\lambda\left(\widetilde{x}_{i t}+\theta_{i t} \frac{d \widetilde{x}_{i t}}{d \theta_{i t}}\right)=0
$$

Since the competitive equilibrium allocation $\widetilde{x}_{t}$ satisfies $D_{i}^{-1}\left(\widetilde{x}_{i t}\right)=c_{i}+\theta_{i t}$, it is the case that $\frac{d \widetilde{x}_{i t}}{d \theta_{i t}}=\frac{1}{D_{i}^{-{ }^{\prime \prime}(.)}}$. The optimum tax is thus such that $\theta_{i t}^{*}=\frac{1-\lambda}{\lambda} \widetilde{x}_{i t} D_{i}^{-1 \prime}($.$) . Consequently$ the optimum tax rate is given by

$$
\frac{\theta_{i t}^{*}}{\widetilde{q}_{i t}}=\frac{\lambda-1}{\lambda} \frac{1}{-\widetilde{\xi}_{D i}},
$$

where $\xi_{D i} \equiv \frac{D_{i}^{-1}(.)}{x_{i t} D_{i}^{-1 \prime}(.)}$ is the elasticity of demand, negative by assumption. $\lambda$ being the unit cost of levying revenues through taxes, it is strictly greater than unity when taxes are distortionary and equals unity if there is a non-distortionary way to collect revenues. Hence, the optimal tax rates on conventional goods $i=1, \ldots, n$ are positive in general, lower than unity, and vanish if $\lambda=1$.

Formula (13) is Ramsey's formula for the optimal commodity tax. It provides an inverse elasticity rule for the case of perfectly-elastic supplies. Since market conditions are unchanged from one date to the other, the taxes and the induced tax rates are constant over time.

\subsection{Optimal taxation of the non-renewable resource}

The first-order condition for an interior solution to the choice of the tax on the resource is

$$
\left[D_{s}^{-1}\left(\widetilde{x}_{s t}\right)-\theta_{s t}-c_{s}\right] \frac{d \widetilde{x}_{s t}}{d \theta_{s t}}-\widetilde{x}_{s t}+\lambda\left(\widetilde{x}_{s t}+\theta_{s t} \frac{d \widetilde{x}_{s t}}{d \theta_{s t}}\right)=0
$$

\footnotetext{
${ }^{9}$ The cost of levying revenues in absence of distortion, which is the marginal utility of income, is unitary. This stems from the linearity of the consumer surplus in the numeraire.
} 
However, since resource supply is determined by condition (6), it follows that $D_{s}^{-1}\left(\widetilde{x}_{s t}\right)-$ $c_{s}-\theta_{s t}=\widetilde{\eta}_{t}$, which is different from zero unlike the corresponding expression in (12). Consequently the Ramsey-type formula obtained for conventional goods does not apply.

If $\lambda=1$, (14) reduces to $\frac{d \widetilde{x}_{s t}}{d \theta_{s t}}=0$. This means that the tax should not distort the Hotelling extraction path. As shown by Dasgupta, Heal and Stiglitz (1981), such a nondistortionary resource tax exists; it must grow at the rate of interest to keep the path of consumer prices unchanged ${ }^{10}: \theta_{s t}^{*}=\theta_{s 0}^{*} e^{r t}$. Since $\theta_{s t}^{*}$ grows at the rate of interest and the resulting $\widetilde{q}_{s t}$ generally grows at a lower rate, the neutral tax rate is rising over time. The only exception is when the marginal cost of extraction is zero so that $\widetilde{q}_{s t}$ grows at the rate of interest and the resulting optimal tax rate is constant.

As shown earlier, when $\lambda=1$, commodity taxes on conventional goods are zero. Hence the totality of the tax burden falls on the non-renewable resource. Since the tax on the resource is neutral in that case, then a value of unity for $\lambda$ is indeed compatible with taxing the natural resource exclusively. Consequently, provided the tax on the nonrenewable resource brings sufficient cumulative revenues, the government should tax the resource exclusively, and should do so while taxing a proportion of the resource rent that remains constant over time.

The maximum revenue such a neutral resource tax can extract is the totality of gross cumulative scarcity rents that would accrue to producers in the absence of a resource tax. Since unit rents are constant in present value, any reserve unit fetches the same rent, whatever the date at which it is extracted. The present value of total cumulative exhaustibility rents is thus $\widetilde{\eta}_{0} S_{0}$ and its maximum possible value $\bar{\eta}_{0} S_{0}$ corresponds to the absence of taxation; the maximum tax revenue that can be raised by a neutral resource tax is thus

$$
\bar{R}_{0}=\bar{\eta}_{0} S_{0}
$$

\footnotetext{
${ }^{10}$ Their proof goes as follows. Assume $\theta_{s t}=\theta_{s 0} e^{r t}$, for any $\theta_{s 0}$ lower than the consumer price exclusive of the marginal cost in absence of any tax on the resource. Then $\widetilde{q}_{s t}=\widetilde{p}_{s t}+\theta_{s t}=c_{s}+\widetilde{\eta}_{t}+\theta_{s t}=$ $c_{s}+\left(\widetilde{\eta}_{0}+\theta_{0 t}\right) e^{r t}$. Therefore, the price with the tax satisfies the Hotelling rule. The exhaustibility constraint must also be satisfied with equality: $\int_{0}^{+\infty} D_{s}\left(\widetilde{q}_{s t}\right) d t=S_{0}$. As a result, the extraction path under this tax is the same as in absence of tax.
} 
This maximum is implemented with a tax equal to the unit rent in the absence of taxation: $\theta_{s t}^{*}=\bar{\eta}_{0} e^{r t}$. Both $\widetilde{\eta}_{0}$ and $\bar{\eta}_{0}$ are determined in Appendix A. If the tax revenues needed by the government are lower than $\bar{R}_{0}$, the level of the neutral resource $\operatorname{tax} \theta_{s t}^{*}$ is set in such a way as to exactly raise the required revenue: $\theta_{s t}^{*}=\theta_{s 0}^{*} e^{r t}$ with

$$
\theta_{s 0}^{*}=\bar{\eta}_{0}-\widetilde{\eta}_{0}=\frac{R_{0}}{S_{0}}
$$

If $R_{0}>\bar{R}_{0}$, revenue needs cannot be met by neutral taxation of the resource sector and $\lambda>1$; this case will be discussed further below. The following proposition summarizes our findings when government revenue needs are low in the sense that $\lambda=1$.

Proposition 1 (Low government revenue needs) The maximum tax revenue that can be raised neutrally from the non-renewable resource sector is $\bar{R}_{0}=\bar{\eta}_{0} S_{0}$ where $\bar{\eta}_{0}$ is the unit present-value Hotelling rent under perfect competition and in the absence of taxation.

1. If and only if $R_{0} \leq \bar{R}_{0}$, government revenue needs are said to be low and $\lambda=1$; if and only if $R_{0}>\bar{R}_{0}$, government revenue needs are said to be high and $\lambda>1$;

2. When $R_{0} \leq \bar{R}_{0}$, the optimum unit tax on the non-renewable resource is positive and independent of demand elasticity while the optimum unit tax on produced goods is zero. The resource tax raises exactly $R_{0}$ over the extraction period.

Proposition 1 indicates that Ramsey's rule must not be applied to any commodity until neutral taxation of the Hotelling commodity has been fully exploited. ${ }^{11}$ As long as the government's revenue needs are low, conventional commodities should not be taxed, while the resource should be taxed according to a rule that has nothing to do with Ramsey's rule and is independent of the elasticity of demand.

\footnotetext{
${ }^{11}$ The fact that neutral taxation of the Hotelling commodity is possible does not mean that neutral profits taxation à la Stiglitz and Dasgupta (1971) or capital levy à la Lucas (1990) have been subrepticiously allowed into the model. It should be clear from the formulation that the result is reached by commodity taxation. Stiglitz and Dasgupta (1971) clearly anticipated such a possibility. Indeed, working in a static framework without any Hotelling resource, they remarked that "One case to which special attention needs to be drawn is that when one of the factors is supplied inelastically. A tax on that factor is like a lump-sum tax in that it results in no distortion." (footnote 6, page 155).
} 
If the government revenue needs are high in the sense that $R_{0}>\bar{R}_{0}$ and $\lambda>1$, revenue needs cannot be met by neutral taxation; then we have shown that both the resource and the conventional goods should be taxed. Furthermore, the question arises whether the government can and should collect more resource revenues by departing from neutral taxation of the resource sector ${ }^{12}$. This possibility was not explored by Dasgupta, Heal and Stiglitz (1981), nor by followers.

If the government was only interested in tax revenues and did not care about welfare, it would be in the position of a monopoly. In the present problem, this will be a limit case applying when tax revenue needs are extreme. In general, however, the situation of the government will combine characteristics of a monopoly and characteristics of an unconstrained welfare-maximizing government.

The neutral tax that maximizes tax revenues does not leave any resource rent to producers: $\widetilde{q}_{s t}=c_{s}+\theta_{s t}$. Assume, as will be seen to be true later on, that the government can maintain this complete appropriation of producers' resource rents while further increasing tax revenues. Then the condition $\widetilde{q}_{s t}=c_{s}+\theta_{s t}$ remains true while $\theta_{s t}$ is further increased in an attempt to extract some of the consumer surplus. This implies that, when $\lambda>1, \widetilde{p}_{s t}=c_{s}, \widetilde{\eta}_{t}=0, \widetilde{x}_{s t}=D_{s}\left(c_{s}+\theta_{s t}\right)$. With $\widetilde{\eta}_{t}=0$, resource extraction is no longer determined by the Hotelling supply condition (6). The finiteness of reserves may still come as a constraint, but as a constraint faced by the government in its attempt to increase cumulative tax revenues rather than as a constraint faced by producers in maximizing cumulative profits. Thus the government's problem is now to maximize (2), not only subject to (4) and (5), but also subject to

$$
\dot{S}_{t}=-\widetilde{x}_{s t}
$$

where $S_{t}$ denotes the size of the remaining depletable stock at date $t$.

\footnotetext{
${ }^{12}$ Clearly, at each date, a non-linear tax on the resource extraction rate reaching the level of the maximum constant neutral tax at the Pareto-optimal extraction rate, would achieve such a goal. However such non-distortionary tax is ruled out in the conventional Ramsey-Pigou optimal taxation analysis. If it was feasible the Ramsey-Pigou problem would be meaningless.
} 
The Hamiltonian is modified to

$$
\mathcal{H}\left(\widetilde{x}_{t}, a_{t}, \theta_{t}, \lambda_{t}, \mu_{t}\right)=\left(C S\left(\widetilde{x}_{t}\right)+P S\left(\widetilde{x}_{t}\right)+\phi\left(\widetilde{x}_{s t}\right)\right) e^{-r t}+\lambda_{t}\left(r a_{t}+\theta_{t} \widetilde{x}_{t}\right)-\mu_{t} \widetilde{x}_{s t},
$$

where $C S\left(\widetilde{x}_{t}\right), P S\left(\widetilde{x}_{t}\right), \phi\left(\widetilde{x}_{s t}\right)$ are defined as before but with $\widetilde{\eta}_{t}=0$, and $\mu_{t}$ is the co-state variable associated with the exhaustibility constraint. From the maximum principle, $\lambda_{t}=\lambda e^{-r t}$, as above, and $\mu_{t}=\mu \geq 0$. If the exhaustibility constraint is binding, that is to say if optimal taxation induces complete exhaustion of the reserves, $\mu>0$; if optimal taxation leads to incomplete exhaustion, then $\mu=0$.

The first-order condition for the choice of the tax on the resource becomes

$$
\left[D_{s}^{-1}\left(\widetilde{x}_{s t}\right)-\theta_{s t}-c_{s}\right] \frac{d \widetilde{x}_{s t}}{d \theta_{s t}}-\widetilde{x}_{s t}+\lambda\left(\widetilde{x}_{s t}+\theta_{s t} \frac{d \widetilde{x}_{s t}}{d \theta_{s t}}\right)=\mu e^{r t} \frac{d \widetilde{x}_{s t}}{d \theta_{s t}} .
$$

Since no resource rent is left to producers above the marginal cost of extraction, $D_{s}^{-1}\left(\widetilde{x}_{s t}\right)-$ $\theta_{s t}-c_{s}=0, \frac{d \widetilde{x}_{s t}}{d \theta_{s t}}=\frac{1}{D_{s}^{-1 /(}(.)}$, and the optimum tax on the resource is thus

$$
\theta_{s t}^{*}=\frac{1}{\lambda} \mu e^{r t}+\frac{\lambda-1}{\lambda} \frac{\widetilde{q}_{s t}}{-\widetilde{\xi}_{D s}} .
$$

Provided the resource is scarce $(\mu>0)$ from the government's point of view, (19) implies that the resource is taxed at a higher rate than would be the case according to (13) for a conventional commodity having the same demand elasticity. Furthermore, while the first term on the right-hand side of (19) is neutral as it rises at the rate of discount, the presence of the second term implies that the tax is not constant in present value, so that it is distortionary in general.

Can the tax revenue maximization motive cause the government to assign no scarcity value to a resource that would otherwise be extracted until exhaustion? The answer is negative. For suppose that $\mu=0$ in (19). This implies that the tax rate is constant over time, so that the extraction rate is also constant and strictly positive, which in turn implies that the exhaustibility constraint must be violated in finite time.

The following proposition summarizes the results on the optimum taxation of the resource when neutral taxation is not sufficient to collect the revenue needs. 
Proposition 2 (High government revenue needs) If $R_{0}>\bar{R}_{0}$, then commodity taxation is distortionary $(\lambda>1)$ and both the non-renewable resource sector and conventional sectors are subject to taxation. In that case:

1. Taxes on conventional commodities are given by Ramsey's rule (13) and the tax on the non-renewable resource is given by (19), where $\lambda$ is determined by the condition that the total tax revenue levied from the non-resource and resource sectors exactly equals $R_{0}$;

2. The non-renewable resource is taxed at a higher rate than a conventional commodity having the same demand elasticity;

3. The after-tax resource rent to producers is nil: $\widetilde{\eta}_{t}=\widetilde{\eta}_{0}=0$;

4. It is never optimal for the government to induce reserves to be left unexploited in the ground.

Propositions 1 and 2 also have implications on the evolution of the total flow of tax revenues over time. When the government's revenue needs are low, the total flow of tax revenues decreases in present value. Indeed, the resource unit tax is constant in present value if (15) applies while extraction diminishes. Tax revenues from conventional sectors being nil, total tax revenues decrease in present value and vanish entirely if the resource is exhausted in finite time. When the government's revenue needs are high, the flow of tax revenues from conventional sectors is constant in current value. If the resource is exhausted in finite time, the total tax revenue flow is thus lower at and after the date of exhaustion than before exhaustion. In either case, the government's assets accumulated at resource exhaustion must be sufficient to ensure that expenditures taking place after exhaustion can be financed.

From Propositions 1 and 2, the resource should be taxed in priority whatever its demand elasticity and whatever the demand elasticity of regular commodities. While this irrelevance of demand elasticities contrasts sharply with standard optimum commodity taxation, it can be given a proper interpretation through Ramsey's lens. Indeed, the 
finiteness of the resource stock implies that the supply of resource is inelastic in the long run. It turns out that the long-run inelasticity of the stock is transmitted to short-run supply by the neutral tax.

When the government cannot avoid the introduction of distortions, as when revenue needs are high, its problem acquires a profit-maximizing dimension. This confers to the optimum commodity taxation a resemblance with monopoly pricing. If the need of tax revenues was extreme, that is to say if $\lambda$ tended toward infinity, the optimum tax rate implied by (19) would be $\mathrm{b}^{13} \frac{\theta_{s t}^{*}}{\widetilde{q}_{s t}}=\frac{1}{-\widetilde{\xi}_{D s}}$, corresponding to static monopoly pricing; indeed, $\frac{\theta_{s t}}{\widetilde{q}_{s t}}=\frac{\widetilde{q}_{s t}-c_{s}}{\widetilde{q}_{s t}}$ is the static Lerner index for the resource industry. Under such extreme condition the optimum resource tax rate would be determined by the same inverse elasticity rule as the tax rate applying to other commodities according to (13).

Since $\frac{1}{\lambda}$ and $\frac{\lambda-1}{\lambda}$ sum to unity, the optimum tax on the resource industry given by (19) is a weighted sum of two elements. The first element $\mu e^{r t}$ can be interpreted as the neutral component of the tax since it rises at the rate of discount as does a neutral Hotelling tax. The second element was just seen to correspond to monopoly pricing. Since $\lambda$ is higher than unity and rises as $R_{0}$ increases, Proposition 3 has been established.

Proposition 3 (Optimal taxation and monopoly pricing) As government revenue needs become higher, the optimum tax rule gives less weight to the neutral component of taxation and more weight to monopoly pricing. When revenue needs are low $(\lambda=1)$, the optimal extraction tax is neutral; when revenue needs are very high $(\lambda \rightarrow \infty)$ the optimal extraction tax is such that the consumer price is the monopoly price.

The resource monopoly literature has shown the exercise of market power by a Hotelling resource monopoly to be constrained by exhaustibility. The sharpest example is Stiglitz (1976) who showed that a resource monopoly facing a constant elasticity of demand and zero extraction costs must adopt the same extraction profile as a competitive firm would; such a monopoly cannot increase its profits above the value of the mine

\footnotetext{
${ }^{13}$ Although $\mu$ varies as $\lambda$ changes, this scarcity rent cannot become infinite as $\lambda \rightarrow \infty$ so that the first term on the right-hand side of (19) indeed vanishes as required for this statement to be true.
} 
under competition by distorting the extraction path. This limitation also applies to the optimum taxation problem. With zero extraction cost and isoelastic extraction, the tax defined by (19) is neutral and rises at the discount rate. We prove that result and make use of it in Section 4, where initial reserves are treated as endogenous.

Although it is standard in the optimal taxation literature ${ }^{14}$ to focus on the demand side and not to mention supply, the initial work by Ramsey also examines the effect of supply elasticity on optimal tax rates. According to Ramsey, when the quantity of a good is inelastic, whether due to demand or due to supply considerations, that good should be taxed at a higher rate than other commodities. Once the mechanism by which long-run resource supply inelasticity results in short-run inelasticity is integrated into the analysis, Ramsey's conclusion also applies to non-renewable resource taxation as well. In the next section, we focus on the role of long-run resource-supply inelasticity. We extend the analysis to the case of increasing marginal costs of production and increasing marginal costs of extraction. This extension will show that short-run supply elasticity does not matter: the finiteness of ultimate reserves implies that non-renewable resources should be taxed in priority. What matters is long-run supply elasticity.

The reader may want to skip the next section and move directly to Section 4 where the Hotelling assumption that reserves are exogenously given is relaxed. Doing away with this assumption introduces the long-run supply elasticity of the resource and also allows us to highlight the distinction between a non-renewable resource and conventional capital.

\section{Supply elasticity: the case of increasing marginal costs}

The assumption of infinite supply elasticity made by so many contributors to the optimum commodity taxation literature may be justified on the ground that they adopt a long-run perspective, where all commodities can be produced at constant marginal costs because all inputs are variable. Does this assumption have any role in generating the results just presented? We now assume that the conventional producible goods are

\footnotetext{
${ }^{14}$ On this, see Gaffney (2009), pages 375-376.
} 
supplied according to the function $S_{i}\left(p_{i t}\right)$, with $S_{i}^{\prime}()>$.0 , for $i=1, \ldots, n$; $S_{i}^{-1}\left(x_{i t}\right)$ is the increasing marginal cost of producing a quantity $x_{i t} \cdot{ }^{15}$ Regarding the non-renewable resource, we assume an increasing marginal cost of extraction. For notational simplicity, this marginal cost is denoted by $S_{s}^{-1}\left(x_{s t}\right)$. However, this does not denote the inverse supply function. In competitive equilibrium, the supply of resource is determined by the "augmented marginal cost" condition:

$$
\widetilde{p}_{s t}=S_{s}^{-1}\left(\widetilde{x}_{s t}\right)+\widetilde{\eta}_{t},
$$

where the current-value Hotelling's rent $\widetilde{\eta}_{t}$ grows at the rate of discount.

The optimal commodity taxation problem of maximizing (2) subject to (4) and (5), and the associated Hamiltonian are only modified to the extent that the producer surplus becomes

$$
P S\left(\widetilde{x}_{t}\right)=\sum_{i=1, \ldots, n, s} \widetilde{p}_{i t} \widetilde{x}_{i t}-\sum_{i=1, \ldots, n} \int_{0}^{\widetilde{x}_{i t}} S_{i}^{-1}(u) d u-\int_{0}^{\widetilde{x}_{s t}}\left(S_{s}^{-1}(u)+\widetilde{\eta}_{t}\right) d u .
$$

Given this change, the structure of the analysis is quite similar to that of the case of constant marginal costs.

\subsection{Optimal taxation of conventional goods}

Assuming that there exist feasible taxes that yield an interior solution to the problem, the first-order condition for the choice of the $\operatorname{tax} \theta_{i t}$ on good $i=1, \ldots, n$ is

$$
\left[D_{i}^{-1}\left(\widetilde{x}_{i t}\right)-\theta_{i t}-S_{i}^{-1}\left(\widetilde{x}_{i t}\right)\right] \frac{d \widetilde{x}_{i t}}{d \theta_{i t}}-\widetilde{x}_{i t}+\lambda\left(\widetilde{x}_{i t}+\theta_{i t} \frac{d \widetilde{x}_{i t}}{d \theta_{i t}}\right)=0 .
$$

Since the competitive equilibrium allocation $\widetilde{x}_{t}$ satisfies $D_{i}^{-1}\left(\widetilde{x}_{i t}\right)=S_{i}^{-1}\left(\widetilde{x}_{i t}\right)+\theta_{i t}$, it follows that $\frac{d \widetilde{x}_{i t}}{d \theta_{i t}}=\frac{1}{D_{i}^{-1 \prime}(.)-S_{i}^{-1 \prime}(.)}$. The optimum tax is thus such that $\theta_{i t}^{*}=\frac{1-\lambda}{\lambda} \widetilde{x}_{i t}\left(D_{i}^{-1 \prime}()-\right.$. $\left.S_{i}^{-1 \prime}().\right)$. Consequently the optimum tax rate is given by

$$
\frac{\theta_{i t}^{*}}{\widetilde{q}_{i t}}=\frac{\lambda-1}{\lambda}\left(\frac{1-\frac{\theta_{i t}^{*}}{\widetilde{q}_{i t}}}{\widetilde{\xi}_{S i}}-\frac{1}{\widetilde{\xi}_{D i}}\right)
$$

where $\xi_{D i} \equiv \frac{D_{i}^{-1}(.)}{x_{i t} D_{i}^{-1 \prime}(.)}$ is the elasticity of demand and $\xi_{S i} \equiv \frac{S_{i}^{-1}(.)}{x_{i t} S_{i}^{-1 \prime}(.)}$ is the elasticity of supply, respectively negative and positive by assumption. As before, $\lambda$ is strictly greater

\footnotetext{
${ }^{15}$ In this respect, our treatment follows Ramsey (1927, page 55).
} 
than unity when taxes are distortionary and equals unity if there is a non-distortionary way to collect revenues.

Formula (23) may be interpreted as Ramsey's formula for the optimal commodity tax (Ramsey, 1927, page 56). It provides an inverse elasticity rule for the case of nonperfectly-elastic supplies.

\subsection{Optimal taxation of the non-renewable resource}

The first-order condition for an interior solution to the choice of the tax on the resource is now

$$
\left[D_{s}^{-1}\left(\widetilde{x}_{s t}\right)-\theta_{s t}-S_{s}^{-1}\left(\widetilde{x}_{s t}\right)\right] \frac{d \widetilde{x}_{s t}}{d \theta_{s t}}-\widetilde{x}_{s t}+\lambda\left(\widetilde{x}_{s t}+\theta_{s t} \frac{d \widetilde{x}_{s t}}{d \theta_{s t}}\right)=0
$$

Since resource supply is determined by condition (20), it follows that $D_{s}^{-1}\left(\widetilde{x}_{s t}\right)-\theta_{s t}-$ $S_{s}^{-1}\left(\widetilde{x}_{s t}\right)=\widetilde{\eta}_{t}$, which is different from zero.

If $\lambda=1,(24)$ reduces to $\frac{d \widetilde{x}_{s t}}{d \theta_{s t}}=0$, implying that the resource must be taxed in a neutral way. As shown earlier, $\bar{\eta}_{0} S_{0}$ the gross (untaxed) scarcity rent, is also the maximum revenue that can be collected in a non-distortionary way. ${ }^{16}$ Therefore, if $R_{0} \leq \bar{\eta}_{0} S_{0}$, the resource is the sole provider of tax revenues as when the elasticity of supply of conventional goods is infinite.

If $R_{0}>\bar{\eta}_{0} S_{0}$, the revenue needs in excess of $\bar{\eta}_{0} S_{0}$ cannot be raised neutrally and $\lambda$ exceeds unity; consequently (24) no longer implies $\frac{d \widetilde{x}_{s t}}{d \theta_{s t}}=0$. In general, the tax on the resource sector should be distortionary as in the previous section. What is new however is that the distortion aims at capturing part of the consumer surplus and part of the producer surplus while no producer surplus was available when marginal extraction and production costs were assumed to be constant.

Because of the long-run inelasticity of the reserves, the resource should be taxed in priority even when supply elasticities in the other sectors are not assumed to be infinite. If the mine can provide sufficient rents, the other commodities are not taxed at all; otherwise, all sectors are taxed in such a way that the distortions are spread across

\footnotetext{
${ }^{16}$ It can be shown that a unit tax growing at the discount rate is neutral under the current assumptions as before.
} 
sectors.

\section{Endogenous reserves}

In order to focus on the role of the long-run supply of reserves, we assume in this section, as in Section 2, that marginal extraction costs are constant, equal to $c_{s} \geq 0$. This means that the supply of the natural resource is only limited by the availability of reserves. As far as produced goods are concerned, their marginal costs of production may be either constant as in Section 2, implying infinite supply elasticity, or rising as in Section 3, implying a finite supply elasticity.

The stock of reserves exploited by a mine does not become available without some prior exploration and development investment. Although exploration for new reserves and exploitation of current reserves often take place simultaneously (e.g. Pindyck, 1978, and Quyen, 1988 ${ }^{17}$ ), a convenient and meaningful simplification consists in representing them as taking place in a sequence, as in Gaudet and Lasserre (1988) and Fischer and Laxminarayan (2005). This way to model the supply of reserves is particularly adapted to the optimum-taxation problem under study because it provides a simple and natural way to distinguish short-run supply elasticity from long-run supply elasticity. It also raises the issue of the government's ability to tax and subsidize, as well as its ability to commit. The issue of commitment does not arise in static treatments of optimum commodity taxation; it arises here because of the intertemporal dimension of the analysis and it is magnified by the sharp distinction our model makes between short-run and long-run supply elasticities in the resource sector.

Most commonly observed extractive resource tax systems feature royalties and levies based on extraction revenues or quantities, often combined with tax incentives to exploration and development. These systems clearly let some rents accrue to producers during the extraction phase and these rents are claimed to be crucial for development and exploration cost recovery. In such systems, governments do not subsidize or otherwise directly help exploration or reserve development on a scale sufficient to compensate

\footnotetext{
${ }^{17}$ See Cairns (1990) for a comprehensive survey of related contributions.
} 
firms for the production of reserves. Firms rely on extraction rents for that.

On the other hand, state-owned extraction sectors are common. A nationalized industry means that no extraction rents are left to producers. Thus two situations are common empirically: in the first instance extraction is taxed in such a way that strictly positive rents are left to firms; in the second instance no extraction rents are left to firms. The results from the previous sections point to the importance of that distinction. Indeed, when $S_{0}$ is given as in the previous sections, if the government has high revenue needs in the sense of Proposition 2, it should tax the totality of resource rents away from producers. If it did so when $S_{0}$ were endogenous, it would remove incentives for producers to generate reserves in the first place. If the government wants to create a tax environment allowing net extraction profits to compensate firms for the cost of reserve production, it must be able to commit, prior to extraction, to a system of ex post extraction taxation that leaves enough rents to producers. Alternatively, if the government taxes away all extraction rents, it must compensate firms by subsidies or tax breaks prior to extraction. In fact we will show that there exists a continuum of mixed systems, combining subsidies toward reserve supply with positive after-tax extraction rents, that achieve the government's objective. These mixed systems are feasible if the government is able to commit to leave firms the prescribed after-tax extraction rent; otherwise, an optimal system relying on reserves supply subsidies exclusively can also achieve the same objective. ${ }^{18}$

For simplicity assume that ex ante reserve producers (explorers) are the same firms as ex post extractors. Assume that the stock of reserves to be exploited is determined prior to extraction by a supply process that reacts to the sum of the subsidies obtained by the firms during the reserve production phase and the cumulative net present-value rents accruing to resource producers during the exploitation stage; also for simplicity,

\footnotetext{
${ }^{18}$ The taxation of profits is compatible with exploration and reserve development expenditures. In such systems, these expenditures are written against profits during the extraction phase and receive a treatment similar to that of other types of investments. We do not consider this option in order to keep adhering with Ramsey's commodity taxation framework. In practice, as Boadway and Flatters (1993) make clear, various forms of commodity taxation are much more prevalent than profit taxation in non-renewable resource sectors.
} 
assume that reserve production is instantaneous.

As not only known reserves but also exploration prospects are finite, the long-run supply of reserves is subject to decreasing returns. Express total cumulative presentvalue rents from extraction as $\eta_{0} S_{0}$. Suppose further that a linear subsidy $\rho$ may be applied to the production of reserves, for a total subsidy of $\rho S_{0}$. Then the initial stock of reserves may be written as a function of $\eta_{0}+\rho$. This function $S\left(\eta_{0}+\rho\right)$ can be interpreted as the long-run after-tax supply of reserves as follows. Suppose that reserves can be obtained, via exploration or purchase, at a cost $E\left(S_{0}\right)$ such that $E(0)=0$, $E^{\prime}\left(S_{0}\right)>0$ for any $S_{0}>0$, and $E^{\prime \prime}()>$.0 . Then the profit from the production of a stock $S_{0}$ of initial reserves is $\left(\widetilde{\eta}_{0}+\rho\right) S_{0}-E\left(S_{0}\right)$. Given $\rho$ and $\widetilde{\eta}_{0}$, its maximization requires $\widetilde{\eta}_{0}+\rho=E^{\prime}\left(S_{0}\right)$. We define $S\left(\widetilde{\eta}_{0}+\rho\right) \equiv E^{\prime-1}\left(\widetilde{\eta}_{0}+\rho\right)$, making the following assumption:

Assumption 1 (Long-run supply) The supply of initial reserves $S$ (.) is continuously differentiable and such that $S(0)=0, S\left(\eta_{0}+\rho\right)>0$ for any strictly positive value of $\eta_{0}+\rho$, and $S^{\prime}\left(\eta_{0}+\rho\right)>0$.

The property $S\left(\eta_{0}+\rho\right)>0$ for any strictly positive value of $\eta_{0}+\rho$ is introduced because it is sufficient to rule out the uninteresting situation where the demand for the non-renewable resource does not warrant the production of any reserves.

\subsection{Optimal resource taxation when a strictly positive rent is left to pro- ducers}

Even when the government can subsidize exploration, i.e. when $\rho>0$, leaving some positive after-tax extraction rent may be desirable for the government. There are two reasons why it is interesting to analyze situations where the government leaves positive extraction rents to producers. First, they are empirically relevant. Second, they will be shown to constitute a general case that includes no-commitment as a limiting case. In this subsection, we assume that $\rho$ is given and is not high enough to remove the need for the government to leave producers positive after-tax extraction rents. Later on, we 
will analyze the choice of $\rho$ and study whether it is desirable for the government to leave positive extraction rents to producers at all.

Ex post, once reserves have been established, producers face a standard Hotelling extraction problem. Consequently, respecting its commitment amounts for the government to choosing a tax profile that leaves producers a Hotelling rent $\widetilde{\eta}_{t}>0$, with $\widetilde{\eta}_{t}=\widetilde{\eta}_{0} e^{r t}$, as defined in (6) and (7), for a total rent commitment of $\widetilde{\eta}_{0} S_{0}$. Clearly, given $\rho$, the level of initial reserves will be determined ex ante by that commitment; it will be denoted $\widetilde{S}_{0}$, with

$$
\widetilde{S}_{0}=S\left(\widetilde{\eta}_{0}+\rho\right)
$$

and discussed further below.

At the extraction stage, the government chooses optimal taxes given $\widetilde{\eta}_{0}$, or, equivalently, given any positive $\widetilde{S}_{0}$. The problem is thus identical to the problem with exogenous reserves analyzed in Section 2, except that the government is now subject to its $e x$ ante rent commitment. The Hamiltonian is thus (17), with $\widetilde{\eta}_{t}=\widetilde{\eta}_{0} e^{r t}>0$ rather than $\widetilde{\eta}_{t}=0:$

$$
\mathcal{H}\left(\widetilde{x}_{t}, a_{t}, \theta_{t}, \lambda_{t}, \mu_{t}\right)=\left(C S\left(\widetilde{x}_{t}\right)+P S\left(\widetilde{x}_{t}\right)+\phi\left(\widetilde{x}_{s t}\right)\right) e^{-r t}+\lambda_{t}\left(r a_{t}+\theta_{t} \widetilde{x}_{t}\right)-\mu_{t} \widetilde{x}_{s t},
$$

where $C S\left(\widetilde{x}_{t}\right), P S\left(\widetilde{x}_{t}\right), \phi\left(\widetilde{x}_{s t}\right)$ are respectively defined by (8), (9) or (21) according to whether marginal costs are constant or rising, and (10), with $\widetilde{\eta}_{t}=\widetilde{\eta}_{0} e^{r t}>0$. The control variables are the taxes $\theta_{t}$.

Suppose, as an assumption to be contradicted, that $\lambda=1$; then, according to Proposition 1, conventional goods are not taxed and a tax is imposed on the resource during the extraction phase to satisfy revenue needs. This reduces the rent accruing to extracting firms and, by (25), reduces the initial amount of reserves relative to the no-tax situation. Consequently, any attempt to satisfy revenue needs by taxing the resource extraction sector results in a distortion, so that, in contradiction with the initial assumption, $\lambda$ is strictly higher than unity whatever the revenue needs. It follows that the tax on conventional goods is given by (13) or by (23) - depending on the assumption made on the cost structure of the conventional sectors - with $\lambda>1$. 
Consider the taxation of the resource sector now, with $\lambda>1$. In Appendix E, we show that the optimal extraction tax differs from its value when reserves are exogenous, in that it now depends on the rent that the government is committed to as follows:

$$
\theta_{s t}^{*}=\frac{1}{\lambda}\left(\mu-\widetilde{\eta}_{0}\right) e^{r t}+\frac{\lambda-1}{\lambda} \frac{\widetilde{q}_{s t}}{-\widetilde{\xi}_{D s}} .
$$

The second term on the right-hand side of that expression is the familiar inverse elasticity rule; it appears in the same form as in Formula (19) describing the resource tax when reserves are exogenous. As in that case the tax rate on the resource thus exceeds the tax rate on a conventional good of identical demand elasticity if and only if the first term is non negative. Such is clearly the case with exogenous reserves when the first term on the right-hand side is $\frac{1}{\lambda} \mu e^{r t}$ but not so with endogenous reserves as the sign of the first term on the right-hand side of $(27)$ depends on the sign of $\left(\mu-\widetilde{\eta}_{0}\right)$. Intuition suggests that the government would not commit ex ante to leaving a unit after-tax rent of $\widetilde{\eta}_{0}$ to firms if this was not at least equal to its ex post implicit valuation $\mu$ of a reserve unit. One can validate this intuition by analyzing the choice of $\widetilde{\eta}_{0}$, which we now turn to.

Let us characterize the ex ante choice of $\widetilde{\eta}_{0}$ for a given level of $\rho .{ }^{19}$ The marginal cost of establishing reserves at a level $S_{0}$ is $E^{\prime}\left(S_{0}\right)=S^{-1}\left(S_{0}\right)$; the total cost of reserves evaluated at date 0 is $\int_{0}^{S_{0}} S_{0}^{-1}(S) d S$. This cost should be deducted from the ex ante objective of the government. The objective should also include the total subsidy payment to producers $\rho S_{0}$. The ex ante problem of the government is thus

$$
\max _{\widetilde{\eta}_{0}, \Theta} \int_{0}^{+\infty} W\left(\widetilde{x}_{t}\right) e^{-r t} d t+\rho \widetilde{S}_{0}-\int_{0}^{\widetilde{S}_{0}} S^{-1}(S) d S
$$

subject to the tax revenue constraint, adapted to take account of the additional liability associated with the subsidy:

$$
\int_{0}^{+\infty} \theta_{t} \widetilde{x}_{t} e^{-r t} d t \geq R_{0}+\rho \widetilde{S}_{0} \equiv R .
$$

Denote by $V^{*}\left(\widetilde{S}_{0}, R ; \rho\right)$ the value of $\int_{0}^{+\infty} W\left(\widetilde{x}_{t}\right) e^{-r t} d t$ maximized with respect to $\theta_{t}$ as just discussed. The constant co-state variable $\mu$ in (26) can be interpreted as giving

\footnotetext{
${ }^{19}$ Clearly the subsidy must be low enough to necessitate the presence of after-tax rents at the extraction stage. This will be addressed further below.
} 
the value $\frac{\partial V^{*}}{\partial \widetilde{S}_{0}}$ of a marginal unit of reserves, while $-\lambda$ gives the marginal impact $\frac{\partial V^{*}}{\partial R}$ of a tightening of the budget constraint. Define $\mathcal{V}\left(\widetilde{S}_{0} ; R_{0}, \rho\right) \equiv V^{*}\left(\widetilde{S}_{0}, R ; \rho\right)$; then $\frac{\partial \mathcal{V}}{\partial \widetilde{S}_{0}}=\frac{\partial V^{*}}{\partial \widetilde{S}_{0}}+\rho \frac{\partial V^{*}}{\partial R}=\mu-\rho \lambda$. As $\widetilde{S}_{0}$ is a free state variable, the transversality condition that applies at $t=0$ is $\frac{\partial \mathcal{V}}{\partial \widetilde{S}_{0}}+\frac{\partial\left(\rho \widetilde{S}_{0}-\int_{0}^{\widetilde{S}_{0}} S^{-1}(S) d S\right)}{\partial \widetilde{S}_{0}}=0$, so that at the optimum

$$
\mu=\lambda \rho+\widetilde{\eta}_{0}
$$

Indeed, as hinted earlier, the marginal unit value of reserves for the government in its taxation exercise exceeds the private marginal cost $\rho+\widetilde{\eta}_{0}$ of developing those reserves by a factor reflecting the cost of raising funds $(\lambda>1)$ to finance the subsidy payment.

With $\mu-\widetilde{\eta}_{0} \geq 0$, it thus follows from (27) and (13) that the tax rate on the resource is higher than the tax rate on a conventional good with the same demand elasticity. Precisely, the unit tax $\theta_{s t}^{*}$ on the resource exceeds the common inverse-elasticity term by $\rho e^{r t}$. This component of the unit tax grows at the discount rate so that, alone, it would leave the extraction profile unchanged. In contrast, the component that is common to the resource tax and the tax on the conventional good normally ${ }^{20}$ causes a distortion to the extraction profile; its value is $\frac{\lambda-1}{\lambda} \frac{\widetilde{q}_{s t}}{-\widetilde{\xi}_{D s}(.)}$, exactly that of a conventional Ramsey tax. This is stated in Proposition 4:

Proposition 4 (Optimal extraction taxes; endogenous reserves) When the supply of reserves is elastic and is subsidized at the unit rate $\rho \geq 0$, while the supply of conventional goods or services is infinitely elastic,

1. The non-renewable resource is taxed at a strictly higher rate than a conventional good or service having the same demand elasticity if $\rho>0$; it is taxed at the same rate if $\rho=0$;

2. The tax rate on the resource is given by (31); it is made up of a non-distortionary component complemented by a Ramsey inverse-elasticity component.

\footnotetext{
${ }^{20}$ As already mentioned an exception arises when the demand has constant elasticity and the extraction cost is zero (Stiglitz, 1976).
} 
Substituting (30) into (27) implies:

$$
\frac{\theta_{s t}^{*}}{\widetilde{q}_{s t}}=\frac{\rho e^{r t}}{\widetilde{q}_{s t}}+\frac{\lambda-1}{\lambda} \frac{1}{-\widetilde{\xi}_{D s}}
$$

where $\widetilde{q}_{s t}=c_{s}+\widetilde{\eta}_{0} e^{r t}+\theta_{s t}^{*}$. Any parametric change $\Delta \rho$ exactly compensated by a one-to-one change $\Delta \widetilde{\eta}_{0}=-\Delta \rho$ and by a change $\Delta \theta_{s t}^{*}=-\Delta \widetilde{\eta}_{0} e^{r t}$ ensures that (31) remains satisfied without any further adjustment. As $\widetilde{\eta}_{0}+\rho$ is then unchanged, this new combination of subsidy, tax, and after-tax rent commands the same reserves level; as $\widetilde{q}_{s t}$ is unchanged it generates the same extraction path. It can be verified that all constraints remain satisfied. In other words the optimum after-tax rent depends on the ex ante subsidy: $\widetilde{\eta}_{0}=\widetilde{\eta}_{0}(\rho)$; similarly $\theta_{s t}^{*}=\theta_{s t}^{*}(\rho)$, with $\frac{d \widetilde{\eta}_{0}(\rho)}{d \rho}=-1$ and $\frac{d \theta_{s t}^{*}(\rho)}{d \rho}=e^{r t}$. However the optimum level of reserves $\widetilde{S}_{0}$ and the equilibrium price profile are independent of $\rho$.

This is true within an admissible range for $\rho$. Indeed the subsidy must not exceed the threshold level above which it would not be necessary for the government to leave firms a rent during the extraction phase. That threshold can be determined as follows. The unit after-tax extraction rent induced by the optimal policy is $\widetilde{\eta}_{0}(\rho)=\bar{\eta}_{0}\left(\widetilde{S}_{0}\right)-\theta_{s 0}^{*}(\rho)=$ $\bar{\eta}_{0}\left(\widetilde{S}_{0}\right)-\theta_{s 0}^{*}(0)-\rho$. Therefore, the condition ensuring that the after-tax rent $\widetilde{\eta}_{0}$ remains strictly positive is

$$
\rho<\bar{\rho} \equiv \bar{\eta}_{0}\left(\widetilde{S}_{0}\right)-\theta_{s 0}^{*}(0),
$$

where $\widetilde{S}_{0}$ must satisfy $(25)$, or $S^{-1}\left(\widetilde{S}_{0}\right)=\bar{\eta}_{0}\left(\widetilde{S}_{0}\right)-\theta_{s 0}^{*}(0)=\bar{\rho}$.

Proposition 5 (Tax-subsidy mix) For $0 \leq \rho \leq \bar{\rho}$, the optimum initial reserve level and the optimum extraction profile are independent of the combination of tax and subsidy by which it is achieved.

An immediate corollary is that subsidies are not necessary to achieve the optimum if the government can commit to extraction taxes that leave sufficient rents to extractors. The extension from $\rho<\bar{\rho}$ to $\rho \leq \bar{\rho}$ removes the necessity of commitment on the government's part. It follows from the fact that $\rho=\bar{\rho}$ combined with $\widetilde{\eta}_{0}=0$ generates initial reserves of $\widetilde{S}_{0}$ by (25). This corresponds to the special case of Section 2 and (19) when initial reserves are set to $\widetilde{S}_{0}$. By Proposition 2, the tax is then given by (19) where 
$\mu=\lambda \bar{\rho}$ according to (30). Thus the observed variety in non-renewable resource taxation systems is not incompatible with optimum Ramsey taxation.

\subsection{The inverse elasticity rule for endogenous non-renewable resources}

Let us come back to the inverse elasticity rule. Setting $\rho=0$ in Formula (31) shows that, when the government does not make use of ex ante subsidies to finance the production of reserves, the taxation of extraction obeys the same inverse elasticity rule as the taxation of conventional goods or services of identical demand elasticity. This result is surprising as it applies when the supply of conventional goods is infinitely elastic while the long-run supply of reserves is subject to decreasing returns. ${ }^{21}$

At the nexus of the puzzle and of its rationalization is the interpretation of Ramsey's rule in the case of a Hotelling resource. The usual interpretation of the inverse elasticity rule is that goods or services whose demand is relatively less elastic should be taxed at a relatively higher rate because this keeps quantities demanded as close as possible to the Pareto optimum, thus balancing the distortions across sectors in the socially least costly way. Here, this interpretation does not apply. As a matter of fact the optimal tax defined by (31) may even be neutral, as when the demand is isoelastic and the marginal extraction cost is zero. As underlined by Stiglitz (1976) in his analysis of monopoly pricing in the Hotelling model, this happens because the time trajectory of the resource monopoly price controls how extraction at any date affects extraction at all other dates. The Ramsey tax would have the standard interpretation if it could be analyzed in isolation. However any amount not extracted at one date must be extracted at some other date; any tax, be it a Ramsey tax, leaves the extraction path undisturbed if it grows at the discount rate (Dasgupta et al., 1981). This is precisely what happens with the Ramsey tax when the demand is isoelastic and the marginal extraction cost is zero. More generally, even when the tax is not neutral, its effect on current extraction cannot be given the standard interpretation in terms of distortion.

\footnotetext{
${ }^{21}$ When the supply of conventional goods is elastic the result is not as clear cut (see $(23)$ ). We come back to that case further below.
} 
The taxation of a non-renewable resource whose supply is elastic induces two types of distortions: the first type, affecting the time profile of extraction given the reserves, has been analyzed extensively by now and should be well understood. Let us turn to the second type of distortion, that affects the level of initial reserves. Initial reserves are determined by the optimum level of the unit after-tax rent $\widetilde{\eta}_{0}$, as that variable determines $\widetilde{S}_{0}$ via $(25)$.

As a matter of fact, $\widetilde{\eta}_{t}$ is present in (31) since $\widetilde{q}_{s t}=c_{s}+\widetilde{\eta}_{t}+\theta_{s t}^{*}$. However, it is very difficult in general to isolate its effect or the determinants of its optimum level because there is an infinity of relationships such as (31) and it is their combined influence over the whole extraction period that determines initial reserves. An exception is the special case of isoelastic demand and zero extraction cost studied by Stiglitz (1976). Under these assumptions, the optimal tax does not cause any distortion in the extraction profile, which provides the ideal laboratory for the analysis of the distortion on initial reserves.

When the tax is neutral at given initial reserves, it grows at the rate of discount, so that it can be characterized at any date by its initial level. Each initial tax level corresponds to a particular tax profile so that alternative profiles can be compared by comparing initial levels. A higher initial tax level implies a lower after-tax rent to firms which implies lower initial reserves by (25). In the spirit of Ramsey taxation, one would then expect the optimal initial tax to be inversely affected by supply elasticity. This is precisely the message of the following expression established in Appendix $\mathrm{H}$ for the optimum initial resource tax rate:

$$
\frac{\theta_{s 0}^{*}}{\widetilde{q}_{s 0}}=\frac{\rho}{\widetilde{q}_{s 0}}+\frac{\lambda-1}{\lambda}\left[\frac{1-\frac{\left(\theta_{s 0}^{*}-\rho\right)}{\widetilde{q}_{s 0}}}{\widetilde{\xi}_{S s}}-\frac{1}{-\widetilde{\xi}_{\bar{D} s}}\right],
$$

where $\widetilde{\xi}_{S s} \equiv \frac{\widetilde{\eta}_{0}+\rho}{\widetilde{S}_{0} S^{-1 \prime}(.)}$ is the long-term elasticity of resource supply measured at the resource scarcity rent (inclusive of subsidies) induced by the tax at the beginning of extraction; and where $\widetilde{\xi}_{\bar{D} s} \equiv\left(\frac{d \widetilde{\bar{D}}_{s}}{d q_{s 0}}\right) \frac{\widetilde{q}_{s 0}}{\widetilde{D}_{s}}$ is the elasticity of the cumulative demand for the resource $\widetilde{\bar{D}}_{s} \equiv \int_{0}^{+\infty} D_{s}\left(\widetilde{q}_{s t}\right) d t$ with respect to the initial price $q_{s 0}$, measured over the path of equilibrium prices $\left\{\widetilde{q}_{s t}\right\}_{t \geq 0}$ induced by the optimal tax.

Keeping in mind that the optimal tax has the same impact for any admissible value 
of $\rho$, let us again assume that $\rho=0$. Then (33) is identical to (23), the expression for the optimum rate of tax that applies to conventional goods whose supply is elastic. Its interpretation is also standard: tax more when elasticity is lower, whether the source of elasticity is on the supply or the demand side. There are two important differences between the Hotelling resource and conventional goods or services though, both having to do with the notions of elasticities involved.

In (33), the supply elasticity measures the long-run adjustment of the stock of initial reserves, allowing all other inputs to adjust, relative to the percentage change in the unit producer rent. This elasticity depends on how sensitive exploration is to the rent. If exploration is relatively insensitive to the rent, then the optimal tax rate on the resource tends to be high relative to the tax rates on conventional producible goods over the entire extraction period. In (23) the concept of supply elasticity is standard; it measures the instantaneous percentage change in production (a flow) relative to the percentage change in the unit producer price. If the elasticity is finite, it must be the case that some input, e.g. the stock of capital, does not fully adjust to price and tax changes, which implies decreasing returns to scale.

Similarly, while the elasticity of demand is the standard notion in (23), its counterpart in (33) is defined as the elasticity of cumulative resource demand - over the whole extraction period - with respect to the initial resource price. In fact (33) and (31) taken at $t=0$ could not both be true were the demand elasticity definitions identical in both expressions.

To recapitulate, we have shown that despite its formal similarity with a static inverse elasticity rule, (31) only partially captures the distortion imposed on the resource sector. In general, the distortion induced by Ramsey taxation of a Hotelling resource affects both the intertemporal extraction profile and the initial level of reserves. In the special case where the extraction profile is undistorted by the tax, we have shown how the initial tax rate should be determined to induce the optimal level of initial reserves. Properly defined demand and supply elasticities affect the resource tax the same way demand and supply elasticities determine the tax on conventional goods and services. In general, 
when the Ramsey tax distorts the extraction profile as well as the optimal initial reserve level, similar forces are at work but cannot be disentangled in a single formula such as (33). This is because the optimum tax rate given by (31) is time dependent and, at any date, reflects the appropriate rates at all other dates. The results are gathered in the following proposition.

Proposition 6 (Time profile and initial reserves) When the supply of reserves is elastic and is subsidized at the unit rate $\rho \geq 0$,

1. The Ramsey tax profile described by (31) implies distortions in both the time profile of extraction and the level of initial reserves;

2. When $\rho=0$, the optimal tax is described by a standard static inverse elasticity rule (31) at any date. However that rule does not provide a precise measure of the distortion to resource extraction at that date;

3. When the demand for the non-renewable resource is isoelastic and the extraction cost is zero, the extraction tax is neutral with respect to the time profile of extraction, while it affects the level of initial reserves. In that case the combined influence of long-run supply elasticity and demand elasticity in the determination of the tax rate is given by (33), the same rule that applies to conventional goods and services whose supply is elastic.

The analogy underlined in Section 2 between Ramsey taxation and monopoly pricing when reserves are exogenous is even more obvious when reserves are endogenous. Take $\rho=0$; for non-renewable resources as for conventional goods, the optimal tax rates distort the price in the direction of the monopoly price by a factor $\frac{\lambda-1}{\lambda}$ that reflects the intensity of the government's revenue needs. Moreover, since the optimum extraction profile does not depend on $\rho$ (by Proposition 5), this is also true when the tax is given by the general form of (31). 


\section{Final remarks}

The above analysis extends naturally to the case of several non-renewable resources. The only difference occurs when taxing resources is sufficient to raise the required revenue $(\lambda=1)$. In this regime, the government is indifferent between taxing one resource at a higher rate than another provided the required tax revenue is raised. Consequently the assignment of taxes to resource sectors is indeterminate to the extent that the tax feasibility constraint is met.

Apart from the exhaustibility constraint, we have treated conventional goods and the resource symmetrically. In particular, after assuming constant marginal costs of production and extraction, we have shown how the results extend to the case where both the production of the conventional goods and the extraction of the resource exhibit convex costs.

The standard Ramsey-Pigou framework used in this paper considers indirect, linear taxes or subsidies on any commodity or service. This includes linear subsidies to the production of natural resource reserves (exploration). In the Ramsey-Pigou framework, the objective of the government is to maximize the welfare of producers and consumers while securing a given level of revenues for the production of public goods. The need to secure revenues confers a profit-maximizing dimension to government taxation decisions. Optimum taxes distort consumer prices away from the Pareto optimum toward the monopoly price. For the Hotelling resource, this means that results from the resource monopoly literature are relevant to Ramsey taxation.

When the supply of initial reserves is perfectly inelastic, we have proven that, however elastic the short-run demands for the conventional goods and for the non-renewable resource, the latter has to be taxed in priority. Precisely, the resource should be the sole taxed commodity unless the required tax revenue exceeds the totality of the rents generated by the untaxed resource. When the required tax revenue is higher than the maximum that can be generated by neutral resource taxation, conventional producible goods and services should contribute to government revenues, but, under constant mar- 
ginal costs and perfectly-elastic short-run supply, the resource should be taxed at a higher rate than conventional producible goods having the same demand elasticity.

When the supply of initial reserves is elastic and determined by the combination of after-tax rents to extraction and ex ante subsidies to reserve production, we have shown that all sectors should be taxed simultaneously whatever the tax revenue needs of the government.

In the absence of any subsidies, provided the government can commit to leaving after-tax rents to firms, the optimum tax rate on resource extraction is determined according to the inverse elasticity rule applying to any conventional good whose supply elasticity is infinite. However, this formal similarity hides a crucial difference: due to the dynamic nature of the extraction problem, a similar rule must hold at all dates during the extraction period. As a result, the distortion to extraction cannot be measured simply according to the tax applying at any particular date, however determined, but also depends on the tax applied at all other dates. If the demand for the non-renewable resource is isoelastic and the marginal extraction cost is zero, this goes as far as implying that the optimal tax, although set according to a standard inverse elasticity rule, does not cause any distortion to the extraction path. We have shown that the distortion imposed on the industry then materializes at the level of reserve production rather than the extraction profile. It can be expressed by the standard inverse elasticity rule applying to elastically supplied conventional goods and services, provided the elasticity concepts are the long-run notions defined in the paper. Both the supply and demand elasticities relevant to the Hotelling resource are elasticities of a stock in response to an after-tax asset price, rather than the flow elasticities encountered in usual Ramsey formulae.

Another remarkable result arising with endogenous reserves is the fact that, although the optimal extraction tax varies according to the reserve subsidy, the optimal amount of initial reserves and the optimal extraction path of these reserves, do not depend on the tax-subsidy combination. As a result, all the tax-induced distortions just described when subsidies are absent, are insensitive to the tax subsidy combination adopted by the government. In particular, a government that were unable to commit to leaving positive 
after-tax rents to firms during the extraction period, could finance reserve production by subsidies exclusively and achieve the same objective as a government that were able to commit. Similarly, a government that could not devote subsidies to reserve production could give the same incentives by committing to limit extraction taxes appropriately. Within the framework of our model, Ramsey taxation is compatible with institutional forms ranging from a nationalized industry, where the entire reserve production effort is subsidized while the total surplus from extraction is taxed away, to a system where firms finance reserve production and are paid back by future extraction rents.

Natural resource reserves are a form of capital while discoveries and extraction are forms of positive and negative investment. While Ramsey taxation rules out the direct taxation of capital and profits, the linear indirect commodity taxes considered in this paper have the ability to tax natural resource rents. We found that resource rents should be taxed prior to introducing distortionary commodity taxes when the initial amount of reserves is exogenous, as anticipated by Stiglitz and Dasgupta (1971). When reserves are endogenous, the situation is close to that analyzed by Chamley (1986) in that the question whether capital should be taxed in the long run arises in a similar fashion. Chamley identified two aspects of capital revenue taxation. In the short run, capital is rigid; this makes it an attractive target for taxation if the objective is to obtain revenues while avoiding distortions. However, in the long run, the constitution of capital relies on investment, and investment becomes less profitable, the more capital is taxed. Chamley finds that the latter effect becomes dominant in the long run and the revenue from capital should not be taxed at all if the horizon of the government is long enough. We find a very different result when capital is a non-renewable natural resource. As per Proposition 4, the natural resource should be taxed whatever the horizon of the government, despite the fact that the supply of reserves is conditional on the tax. The reason is resource scarcity. While Chamley's capital can be produced without limit under constant returns to scale, reserves, although endogenous, are produced under conditions of decreasing returns because exploration prospects are not unlimited. The supply of non-renewable natural resources is not infinitely elastic in the very long run. 


\section{APPENDICES}

\section{A The Hotelling rent and the neutral tax}

This Appendix defines the Hotelling rent with tax $\widetilde{\eta}_{0}$ and the Hotelling rent without $\operatorname{tax} \bar{\eta}_{0}$ in competitive equilibrium. In competitive equilibrium with linear taxation, Hotelling's current-value unit rent to producers equals producer price minus marginal cost. At time zero, with constant unit extraction cost, this is $\widetilde{\eta}_{0}=\widetilde{q}_{s 0}-\theta_{s 0}-c_{s}$. As the rent is constant in present value, $\widetilde{\eta}_{0}$ measures the present value rent; it can be computed as follows.

If there exists a finite choke price $\bar{q}=D_{s}^{-1}(0)$ for the resource, the resource will be depleted in finite time, at a date $\widetilde{T}>0$ such that $\widetilde{q}_{s} \widetilde{T}=\bar{q}$, where $\widetilde{T}$ is defined by the condition that reserves are exactly exhausted over the period $[0, \widetilde{T}]: \int_{0}^{\widetilde{T}} D_{s}\left(\widetilde{q}_{s t}\right) d t=S_{0}$, with $\widetilde{q}_{s t}-\theta_{s t}-c_{s}=\left(\bar{q}-\theta_{s \widetilde{T}}-c_{s}\right) e^{-r(\widetilde{T}-t)}$. At time zero, the rent is thus $\widetilde{\eta}_{0}\left(S_{0}\right)=$ $\widetilde{q}_{s 0}-\theta_{s 0}-c_{s}=\left(\bar{q}-\theta_{s \widetilde{T}}-c_{s}\right) e^{-r \widetilde{T}}$. If there is no finite choke price for the resource and the resource is not exhausted in finite time, then similar conditions must hold in the limit and define the present-value rent $\widetilde{\eta}_{0}\left(S_{0}\right)$ implicitly: $\lim _{T \rightarrow+\infty} \int_{0}^{T} D_{s}\left(\widetilde{\eta}_{t}+\theta_{s t}+c_{s}\right) d t=S_{0}$, where $\widetilde{\eta}_{t}=\widetilde{\eta}_{0} e^{r t}$. It can be shown that $\widetilde{\eta}_{0}$ is a positive and decreasing function of $S_{0}$.

The maximum value that can be raised from the mine by non-distortionary taxation is its discounted cumulative rent under competitive extraction and in the absence of taxation. That is $\bar{\eta}_{0}\left(S_{0}\right)=\widetilde{\eta}_{0}\left(S_{0}\right)$, where $\widetilde{\eta}_{0}$ is computed as above for the values of $\widetilde{q}_{s t}$ implied by $\theta_{s t}=0 \forall t$. The present value of the mine in the absence of tax is thus $\bar{\eta}_{0}\left(S_{0}\right) S_{0}$.

If taxes are neutral, $\theta_{s t}=\theta_{s 0} e^{r t}$ and part of the unit scarcity rent is captured. The present-value of the net-of-tax unit rent earned by the owner of the mine is thus $\widetilde{\eta}_{0}\left(S_{0}\right)=\bar{\eta}_{0}\left(S_{0}\right)-\theta_{s 0}$ and the after-tax present value of the mine is $\widetilde{\eta}_{0}\left(S_{0}\right) S_{0}$.

\section{B Proof of Proposition 1}

1. We have shown in the main text that $\lambda=1$ implies $\theta_{i}^{*}=0, i=1, \ldots, n$, and $\theta_{s t}^{*}=\theta_{s 0}^{*} e^{r t}$, so that the totality of tax revenues is raised from the resource sector. Moreover, we have argued that, if $\lambda=1$, it must be the case that $R_{0} \leq \bar{\eta}_{0} S_{0}$. The contrapositive of that statement is that if $R_{0}>\bar{\eta}_{0} S_{0}$, then $\lambda>1$. In that case, we have shown in the main text that $\theta_{i}^{*}>0, i=1, \ldots, n$, and that $\theta_{s t}^{*}$ must be set in such a way as to raise more than $\bar{\eta}_{0} S_{0}$ from the resource sector.

There remains to show that $R_{0} \leq \bar{\eta}_{0} S_{0}$ implies $\lambda=1$. Assume $R_{0} \leq \bar{\eta}_{0} S_{0}$ and $\lambda>1$. Then taxes on conventional goods $\theta_{i}^{*}, i=1, \ldots, n$, raise a strictly positive revenue, causing distortions. Since it is possible to generate $\bar{\eta}_{0} S_{0} \geq R_{0}$ without imposing any distortions by taxing the natural resource, this cannot be optimal. Hence, $R_{0} \leq \bar{\eta}_{0} S_{0}$ implies $\lambda=1$. 2. Shown in the main text.

\section{Proof of Proposition 2}

1. As shown in the main text, when $\lambda>1$, the optimum tax rate on conventional good $i=1, \ldots, n$ is $\theta_{i t}^{*}$ as given in (13) and depends on $\lambda$. The optimum tax on the resource 
is given by (19), where $\mu>0$ is determined to satisfy (1) with equality. Together, taxes on conventional goods and the tax on the resource must exactly raise $R_{0}>\bar{\eta}_{0} S_{0}$, which requires that $\sum_{i=1, \ldots, n, s} \int_{0}^{+\infty} \theta_{i t}^{*} \widetilde{x}_{i t} e^{-r t} d t=R_{0}$. Substituting for $\theta_{i t}^{*}$ implicitly defines $\lambda$. $2-4$. Shown in the main text.

\section{Proof of Proposition 3}

When $\lambda=1$, the second term in the right-hand side of (19) vanishes. Hence, the optimal tax rises at the rate of discount and is thus neutral. In the main text, we have shown that when $\lambda \rightarrow \infty$ the optimal tax rate is the reciprocal of the price elasticity of demand. When extraction rents are zero, we have also shown that this tax rate is the static Lerner index and that the resulting consumer price $\widetilde{q}_{t}$ is the static monopoly price.

\section{E Proof of Expressions (27) and (30)}

The Hamiltonian (26) associated with the ex post problem is identical to (17). Hence, the application of the maximum principle also gives $\lambda_{t}=\lambda e^{-r t}$ and $\mu_{t}=\mu$. The first-order condition for the choice of the tax is also (18):

$$
\left[D_{s}^{-1}\left(\widetilde{x}_{s t}\right)-\theta_{s t}-c_{s}\right] \frac{d \widetilde{x}_{s t}}{d \theta_{s t}}-\widetilde{x}_{s t}+\lambda\left(\widetilde{x}_{s t}+\theta_{s t} \frac{d \widetilde{x}_{s t}}{d \theta_{s t}}\right)=\mu e^{r t} \frac{d \widetilde{x}_{s t}}{d \theta_{s t}} .
$$

However, unlike in Section 2, the first term on the left-hand side is not zero since the government is subject to its ex ante commitment: $D_{s}^{-1}\left(\widetilde{x}_{s t}\right)-\theta_{s t}^{*}-c_{s}=\widetilde{\eta}_{t}=\widetilde{\eta}_{0} e^{r t}>0$. At this stage, this commitment determines $\widetilde{\eta}_{0}$. Therefore, $\frac{d \widetilde{x}_{s t}}{d \theta_{s t}}=\frac{1}{D_{s}^{-1}(.)}$. Substituting these two equalities into the first-order condition and rearranging gives (27), where $\xi_{D s} \equiv \frac{q_{s t}}{x_{s t} D_{s}^{-11}(.)}$.

In the main text, we have shown that the ex post unitary present-value of developed reserves to the government is $\mu=\lambda \rho+\widetilde{\eta}_{0},(30)$. Substituting $\mu-\widetilde{\eta}_{0}=\lambda \rho$ into (27) and dividing all terms by $\widetilde{q}_{s t}$ immediately give $(31)$.

\section{F Proof of Proposition 4}

1. Shown in the main text.

2. This is a restatement of (31), which has been proven in Appendix E.

\section{G Proof of Proposition 5}

The Proposition is shown in the main text.

\section{H Proof of Expression (33)}

Expression (33) is established under the assumption that extraction cost is zero, $c_{s}=0$, and that the demand for the resource is isoelastic, $\xi_{D s}\left(q_{s t}\right)=\xi_{D s}$.

In the main text, we have argued that in this case the optimal extraction unit tax grows at the rate of interest. Indeed, $\widetilde{q}_{s t}=\widetilde{\eta}_{0} e^{r t}+\theta_{s t}^{*}$. Substituting into (27) and 
rearranging while taking account of the constancy of $\widetilde{\xi}_{D s}$, one immediately obtains $\theta_{s t}^{*}$ as the product of a constant term with $e^{r t}$. Hence,

$$
\theta_{s t}^{*}=\theta_{0}^{*} e^{r t}
$$

where $\theta_{0}^{*}$ is to be determined.

The first-order condition for the ex ante static maximization of (28) with respect to $\theta_{0}^{*}$ subject to (29), taking the ex post solution (H.1) into account is

$$
\begin{aligned}
\int_{0}^{+\infty} \frac{d W\left(\widetilde{x}_{s t}\right)}{d \theta_{s 0}} e^{-r t} d t+\rho \frac{d \widetilde{S}_{0}}{d \theta_{s 0}}- & S^{-1}(.) \frac{d \widetilde{S}_{0}}{d \theta_{s 0}} \\
& +\lambda\left(\int_{0}^{+\infty}\left(\widetilde{x}_{s t} e^{r t}+\theta_{s 0}^{*} \frac{d \widetilde{x}_{s t}}{d \theta_{s 0}} e^{r t}\right) e^{-r t} d t-\rho \frac{d \widetilde{S}_{0}}{d \theta_{s 0}}\right)=0
\end{aligned}
$$

where $\frac{d W\left(\widetilde{x}_{s t}\right)}{d \theta_{s 0}} e^{-r t}=\left(D_{s}^{-1}\left(\widetilde{x}_{s t}\right)-\theta_{s 0}^{*} e^{r t}\right) \frac{d \widetilde{x}_{s t}}{d \theta_{s 0}} e^{-r t}-\widetilde{x}_{s t}=\widetilde{\eta}_{0} \frac{d \widetilde{x}_{s t}}{d \theta_{s 0}}-\widetilde{x}_{s t}$ and where $S^{-1}()=$. $\widetilde{\eta}_{0}+\rho$. Substituting, one has

$$
\int_{0}^{+\infty}\left(\widetilde{\eta}_{0} \frac{d \widetilde{x}_{s t}}{d \theta_{s 0}}-\widetilde{x}_{s t}\right) d t-\widetilde{\eta}_{0} \frac{d \widetilde{S}_{0}}{d \theta_{s 0}}+\lambda\left(\int_{0}^{+\infty}\left(\widetilde{x}_{s t}+\theta_{s 0}^{*} \frac{d \widetilde{x}_{s t}}{d \theta_{s 0}}\right) d t-\rho \frac{d \widetilde{S}_{0}}{d \theta_{s 0}}\right)=0 .
$$

Integrating with $\int_{0}^{+\infty} \widetilde{x}_{s t} d t=\widetilde{S}_{0}$ and $\int_{0}^{+\infty} \frac{d \widetilde{x}_{s t}}{d \theta_{s 0}} d t=\frac{d \widetilde{S}_{0}}{d \theta_{s 0}}$ and rearranging give

$$
\theta_{s 0}^{*}=\rho-\frac{(\lambda-1)}{\lambda} \frac{\widetilde{S}_{0}}{\frac{d \widetilde{S}_{0}}{d \theta_{s 0}}} .
$$

In long-run market equilibrium $S^{-1}\left(\widetilde{S}_{0}\right)=\widetilde{\eta}_{0}+\rho$ and $\int_{0}^{+\infty} D_{s}\left(\widetilde{\eta}_{t}+\theta_{s t}^{*}\right) d t=\int_{0}^{+\infty} D_{s}\left(\left(\widetilde{\eta}_{0}+\right.\right.$ $\left.\left.\theta_{s 0}^{*}\right) e^{r t}\right) d t=\widetilde{S}_{0}$. It follows by differentiation with respect to $\theta_{s 0}$ that $S^{-1 \prime}(.) \frac{d \widetilde{S}_{0}}{d \theta_{s 0}}=$ $\frac{d \widetilde{\eta}_{0}}{d \theta_{s 0}}$ and $\left(\frac{d \widetilde{\eta}_{0}}{d \theta_{s 0}}+1\right) \int_{0}^{+\infty} D_{s}^{\prime}(.) e^{r t} d t=\frac{d \widetilde{S}_{0}}{d \theta_{s 0}}$. Substituting in $\frac{d \widetilde{\eta}_{0}}{d \theta_{s 0}}$, one obtains $\frac{d \widetilde{S}_{0}}{d \theta_{s 0}}=$ $\frac{\int_{0}^{+\infty} D_{s}^{\prime}(.) e^{r t} d t}{1-S^{-1 \prime}(.) \int_{0}^{+\infty} D_{s}^{\prime}(.) e^{r t} d t}$. Introducing this expression into (H.2) yields

$$
\theta_{s 0}^{*}=\rho+\frac{\lambda-1}{\lambda}\left[\widetilde{S}_{0} S^{-1 \prime}(.)-\frac{\widetilde{S}_{0}}{\int_{0}^{+\infty} D_{s}^{\prime}(.) e^{r t} d t}\right]
$$

from which (33) is derived after substituting the expressions for $\widetilde{\xi}_{S s}$ and $\widetilde{\xi}_{\bar{D} s}$ defined in the main text. To do so, the latter elasticity should be developed as follows. In equilibrium, under the optimal resource tax (H.1), $\widetilde{q}_{s t}=\left(\widetilde{\eta}_{0}+\theta_{0}^{*}\right) e^{r t}=\widetilde{q}_{s 0} e^{r t}$. From the definition of $\bar{D}_{s}$, it follows that $\widetilde{\bar{D}}_{s}=\int_{0}^{+\infty} D_{s}\left(\widetilde{q}_{s t}\right) d t=\widetilde{S}_{0}$. Therefore, $\widetilde{\xi}_{\bar{D} s}=\left(\frac{d \int_{0}^{+\infty} D_{s}\left(\widetilde{q}_{s 0} e^{r t}\right) d t}{d \widetilde{q}_{s 0}}\right) \frac{\widetilde{q}_{s 0}}{\widetilde{S}_{0}}=$ $\frac{\int_{0}^{+\infty} D_{s}^{\prime}(.) e^{r t} d t \widetilde{q}_{s 0}}{\widetilde{S}_{0}}$.

\section{Proof of Proposition 6}

The proposition summarizes findings established in the main text. 


\section{References}

Aronsson, T., and T. Sjögren (2003), "Income Taxation, Commodity Taxation and Provision of Public Goods under Labor Market Distortions", FinanzArchiv, 59: 347-370.

Atkinson, A.B., and J.E. Stiglitz (1976), "The Design of Tax Structure: Direct versus Indirect Taxation", Journal of Public Economics, 6: 55-75.

Atkinson, A.B., and J.E. Stiglitz (1980), Lectures on Public Economics, McGraw-Hill, London.

Baumol, W.J., and D.F. Bradford (1970), "Optimal Departures From Marginal Cost Pricing", American Economic Review, 60: 265-283.

Belan, P., S. Gauthier and G. Laroque (2008), "Optimal Grouping of Commodities for Indirect Taxation", Journal of Public Economics, 92: 1738-1750.

Bergstrom, T.C. (1982), "On Capturing Oil Rents with a National Excise Tax", American Economic Review, 72: 194-201.

Berndt, E.R., and D.O. Wood (1975), "Technology, Prices, and the Derived Demand for Energy", Review of Economics and Statistics, 57: 259-268.

Blomquist, S., and V. Christiansen (2008), "Taxation and Heterogeneous Preferences", FinanzArchiv, 64: 218-244.

Boadway, R.W., and F. Flatters (1993), "The Taxation of Natural Resources: Principles and Policy Issues", WPS 1210, Policy Research Department, The World Bank.

Boadway, R.W., M. Marchand and P. Pestieau (1994), "Towards a Theory of the DirectIndirect Tax Mix", Journal of Public Economics, 55: 71-88.

Cairns, R.D. (1990), "The Economics of Exploration for Non-renewable Resources", Journal of Economic Surveys, 4: 361-395.

Chamley, C. (1986), "Optimal Taxation of Capital Income in General Equilibrium with Infinite Lives", Econometrica, 54: 607-622.

Christiansen, V. (1984), "Which Commodity Taxes Should Supplement the Income Tax?", Journal of Public Economics, 24: 195-220.

Cremer, H., and F. Gahvari (1995), "Uncertainty and Optimal Taxation: In Defense of Commodity Taxes", Journal of Public Economics, 56: 291-310.

Cremer, H., F. Gahvari and J.-C. Rochet (2001), "Direct versus Indirect Taxation: The Design of the Tax Structure Revisited", International Economic Review, 42: 781-799.

Dasgupta, P.S., G.M. Heal and J.E. Stiglitz (1981), "The Taxation of Exhaustible Resources", NBER Working Papers \#436, Cambridge. 
Dasgupta, P.S., and J.E. Stiglitz (1972), "On Optimal Taxation and Public Production", Review of Economic Studies, 39: 87-103.

Fischer, C., and R. Laxminarayan (2005), "Sequential Development and Exploitation of an Exhaustible Resource: Do Monopoly Rights Promote Conservation?", Journal of Environmental Economics and Management, 49: 500-515.

Gaffney, M. (2009), "The Hidden Taxable Capacity of Land: Enough and to Spare", International Journal of Social Economics, 36: 328-411.

Gaudet, G., and P. Lasserre (1988), "On Comparing Monopoly and Competition in Exhaustible Resource Exploitation", Journal of Environmental Economics and Management, 15: 412-418.

Kaplow, L. (2006), "On the Undesirability of Commodity Taxation even when Income Taxation is not Optimal", Journal of Public Economics, 90: 1235-1250.

Konishi, H. (1995), "A Pareto-Improving Commodity Tax Reform under a Smooth Nonlinear Income Tax", Journal of Public Economics, 56: 413-446.

Krichene, N. (2002), "World Crude Oil and Natural Gas: A Demand and Supply Model", Energy Economics, 24: 557-576.

Lewis, T.R., S.A. Matthews and H.S. Burness (1979), "Monopoly and the Rate of Extraction of Exhaustible Resources: Note", American Economic Review, 69: 227-230.

Lucas, R.E. (1990), "Supply-Side Economics: An Analytical Review", Oxford Economic Papers, 42: 293-316.

Mirrlees, J.A. (1976), "Optimal Tax Theory: A Synthesis", Journal of Public Economics, 6: $327-358$.

Naito, H. (1999), "Re-Examination of Uniform Commodity Taxes under a Non-Linear Income Tax System and its Implication for Production Efficiency", Journal of Public Economics, 71: 165-188.

Pigou, A.C. (1928), A Study in Public Finance, Macmillan, New York.

Pindyck, R.S. (1978), "The Optimal Exploration and Production of Nonrenewable Resources", Journal of Political Economy, 86: 841-861.

Pindyck, R.S. (1979), The Structure of World Energy Demand, MIT Press, Cambridge.

Quyen, N.V. (1988), "The Optimal Depletion and Exploration of a Nonrenewable Resource", Econometrica, 56: 1467-1471.

Ramsey, F.P. (1927), "A Contribution to the Theory of Taxation", Economic Journal, 37: 47-61. 
Saez, E. (2002), "The Desirability of Commodity Taxation under Non-Linear Income Taxation and Heterogeneous Tastes", Journal of Public Economics, 83: 217-230.

Saez, E. (2004), "Direct or Indirect Tax Instruments for Redistribution: Short-Run versus Long-Run", Journal of Public Economics, 88: 503-518.

Stiglitz, J.E. (1976), "Monopoly and the Rate of Extraction of Exhaustible Resources", American Economic Review, 66: 655-661.

Stiglitz, J.E., and P.S. Dasgupta (1971), "Differential Taxation, Public Goods, and Economic Efficiency", Review of Economic Studies, 38: 151-174. 